Biomed. SB

267

W171c

1907.

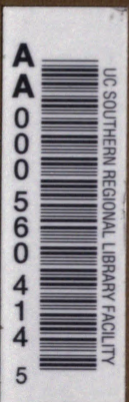

ornia

nal

y 
$\int_{1 \forall J \cdot 10^{\text {RARYOF }}}$ $4 y 917: 34)^{4}$
亿HEUNIVERSII,
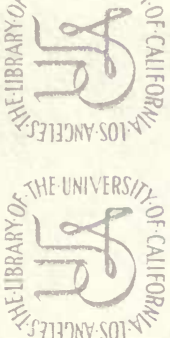

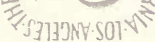
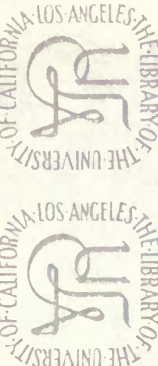

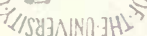
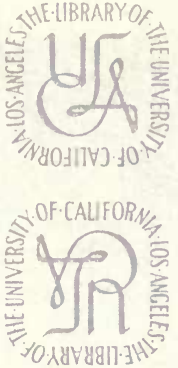
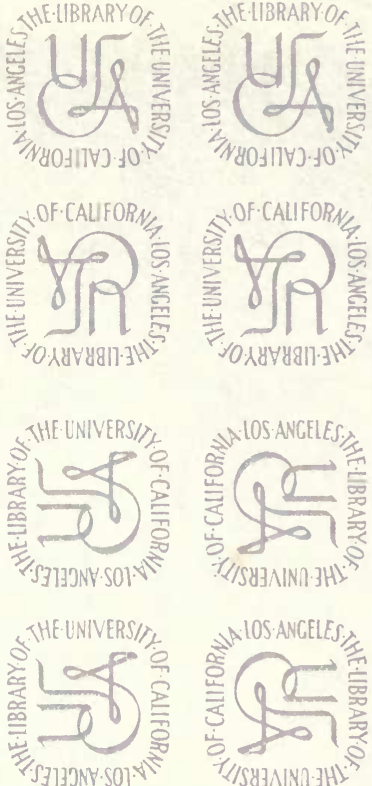
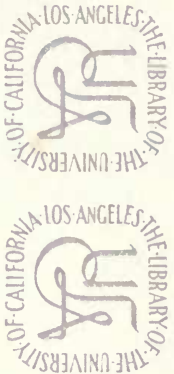
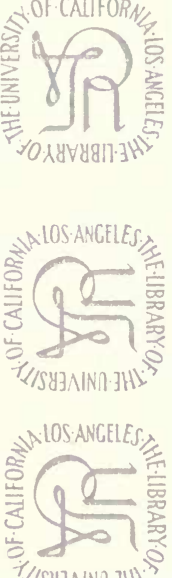

Y/SYININA JHD
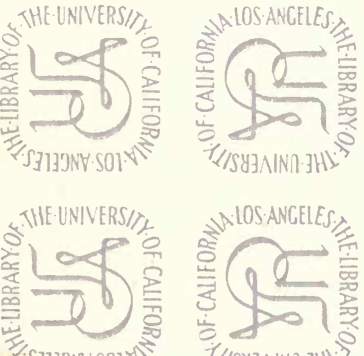

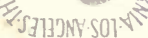
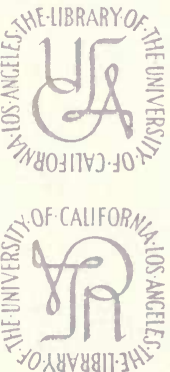
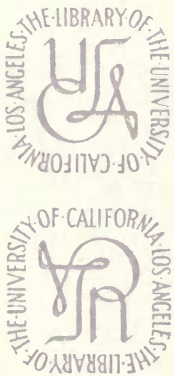

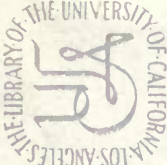

THE UNIVERSIS,

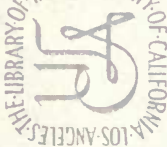

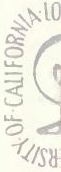

ME:

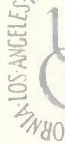

40

ANGEIES.
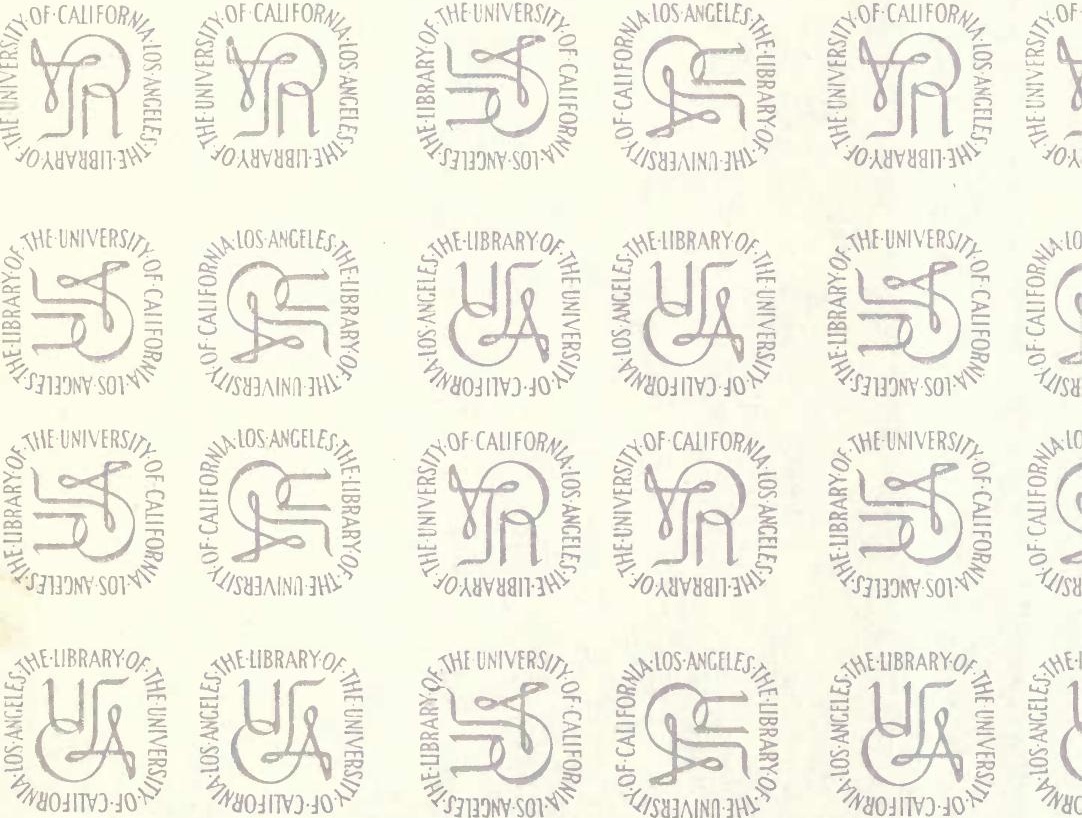

$\frac{\text { ANGEIES. }}{0}$ NINA $3 H$ S'

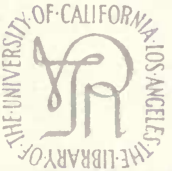

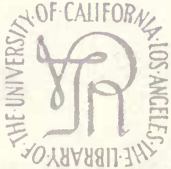

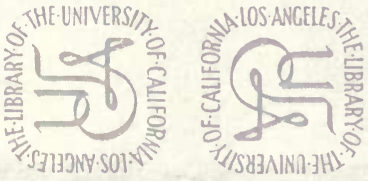

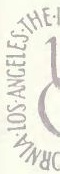

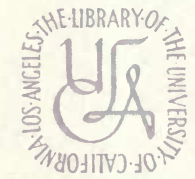

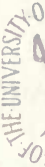






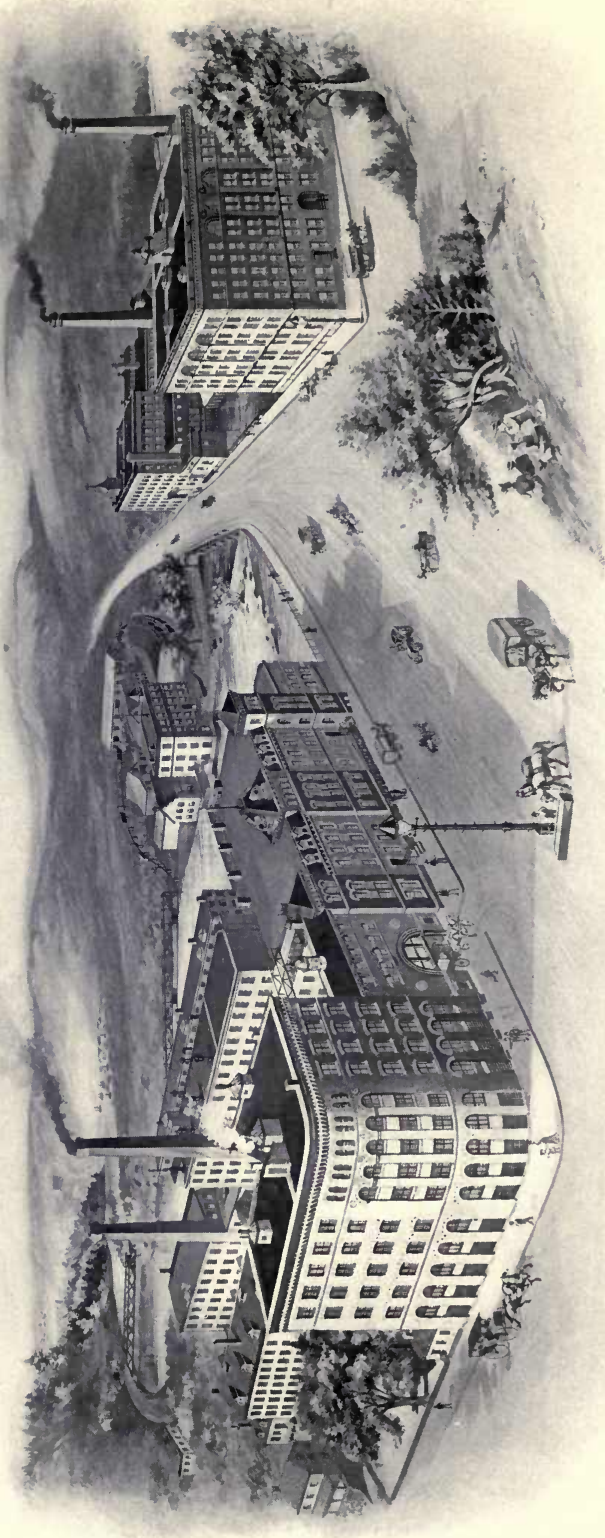




\section{Cocoa and Chocolate}

\section{A short bistory of their production and use}

Rebiect Edition

With numerous illustrations of the Cocoa Tree and its products; and of Walter Baker \& Co.'s manufactory, the oldest and largest establishment of its kind on this continent

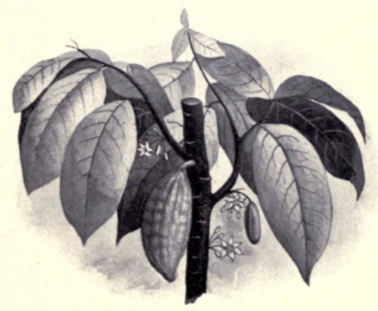

DORCHESTER, MASS.

Walter Baker \& Co. Limited

I907 
Copyright, I907,

By WALTER BaKer \& COMPANy LTD. 
HIS publication is made up in part of original matter and in part of matter reprinted from three of our previous publications, now out of print, namely: “Cocoa and Chocolate: A Short History of Their Production and Use," - a I 2 mo of 152 pages, published in I886; "The Chocolate Plant and Its Products," - a small 4 to of 40 pages, published in 1891 ; and "Cocoa and Chocolate: A Short History of Their Production and Use," a quarto of 72 pages, first printed in I899 and reprinted in I90I and I904. Copies of them can be found in many of the public and school libraries in the United States.

We have included in this work some new views of our mills and workrooms, and also some engravings from photographs taken in the West Indies and in Ceylon, showing the present methods of gathering and curing the fruit of the cocoa tree.

As even the standard dictionaries fail to give the exact meanings of the words "cocoa" and "chocolate," we give here an accurate definition of those terms :-

CocoA. - The commercial name given (I) to the seeds of the small tropical tree known to botanists as Theobroma Cacao; (2) to the cracked or coarsely ground product of the roasted seeds, sometimes designated more particularly as "cocoa nibs," or "cracked cocoa"; (3) to the finely pulverized product of the roasted seeds from which a portion of the fat has been removed, sometimes designated as "breakfast cocoa" or "powdered cocoa."

Chocolate. - ( $\mathrm{I}$ ) The solid or plastic mass produced by grinding to fineness the kernel of the roasted seeds of Theobroma Cacao without removing any of the fat, sometimes called "plain chocolate" or "bitter chocolate"; (2) the same product to which have been added sugar and various flavoring substances, sometimes known as "sweet chocolate" or "vanilla chocolate."

WALTER BAKER \& CO. LTD. 


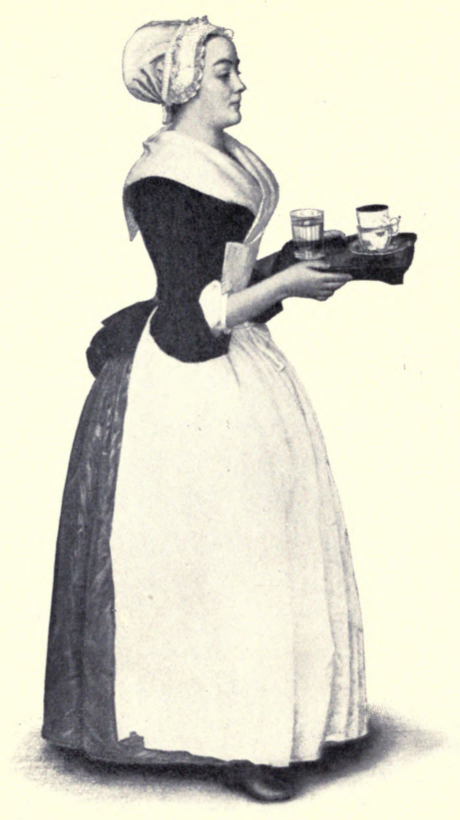

REGISTERED U. S. PATENT OFFICE.

WALTER BAKER \& CO. LTD.

[Copied from Liocard's famous painting of "La Belle Chocolatiere," in the Dresden Gallery.] 


\section{COCOA AND CHOCOLATE.}

I.

PRODUCTION AND CONSUMPTION.

$\mathrm{D}$

URING the last twenty-five years the consumption of cocoa in various forms has increased to an extraordinary extent not only in this country, but in the United Kingdom and Germany - countries in which the greatest progress is being made in the science of nutrition, and in the inventions which have done so much to cheapen the cost and improve the quality of articles of food. This increase in consumption is due to several causes, among the most prominent of which are (I) a reduction in the retail price, bringing it within the means of the poorer classes; (2) a more general recognition of the value of cocoa as an article of food, and (3) improvements in methods of preparation, by which it is adapted to the wants of the different classes of consumers.

There is no doubt that, if it had not been for the monopoly of the production which Spain long possessed, and which kept the price, on its introduction into England, at a point where only the rich could afford to buy it, cocoa would have come into as general use there as it did in Spain, and would, perhaps, have been received with more faror than tea or coffee, which were introduced about the same time.

It appears that, in the time of Charles II., the price of the best chocolate (very crude undoubtedly, as compared with the present manufactures) was $6 \mathrm{~s} .8 \mathrm{~d}$. a pound, which, if we take into account the greater purchasing power of money at that time, would be equal to at least $\$ 5.00$ a pound at this time for a very coarse article.

Ilumboldt estimated the consumption of cocoa in Europe, in r\$o6, as $23,000,000$ pounds per annum, of which from $6,000,000$ to 9,000,000 were supposed to be consumed in Spain. The estimated consumption in Europe at the present time is over $170,000,000$ pounds. 
A recent estimate of the total amount of crude cocoa exported from the tropical regions in which it is grown, based partly on official figures and partly on expert estimates, is about $300,000,000$ pounds per annum. In the report of the U. S. Bureau of Statistics for the fiscal year ending June 30 , 1906, the principal importations of crude cocoa into this country are given as follows: British West Indies, 25,933,087 pounds; other West Indies, I0,389,576; Brazil, I2,064,302; other South American countries of which Ecuador, next to Brazil, furnishes the largest supply, I8,028,265; Europe, principally from the Portuguese island of San Thomé on the West Coast of Africa, I 2,794,055.

In the United Kingdom the amount consumed in 183 I was only $1 / 4$ of an ounce for each inhabitant. In 1902 it had risen to about 17 ounces : that is, about $45,500,000$ pounds. The percentage of increase since 1860 has been much greater than that of tea or coffee. In that year the consumption of tea was 2.67 pounds for each inhabitant; of coffee, I.23 pounds; of cocoa, 2 ounces. In I903, the consumption of tea was 6.03 pounds for each inhabitant; of coffee, only 12 ounces : of cocoa, about $I 7$ ounces. It appears from this that in Great Britain and Ireland cocoa is actually taking the place of coffee, the per capita use of the former having increased about 750 per cent., while the per capita use of the latter has greatly decreased.

In the United States the increased consumption of cocoa in recent years has been even more striking. The amount retained for home consumption in $\mathrm{I} 860$ was only $\mathrm{I}, \mathrm{I} 8 \mathrm{I}, 054$ pounds, or $\%$ of an ounce for each inhabitant. The average annual consumption for the three years, 1904, 1905, and 1906, amounted to $73,034,272$ pounds. ${ }^{1}$ This shows an increase greatly in excess of the increase during the same period in the consumption of coffee and tea. In 1860 , the consumption of coffee per capita was 5.79 pounds; in 1906 it was about II pounds. The consumption of tea in 1860 was about $131 / 2$ ounces per capita; in 1903 it was about 17 ounces. The consumption of cocoa 
had risen during the same period from $3 \%$ of an ounce to over $\mathrm{I}_{4}$ ounces per capita.

Statements in the press and in the reports of the Pure Food Commissioners show that there are on the market at this time many cocoas and chocolates which have been treated with adulterants, more or less injurious to health, for the purpose of cheapening the cost and giving a fictitious appearance of richness and strength. The safest course for consumers, therefore, is to buy goods bearing the name and trademark of a well-known and reputable manufacturer, and to make sure by a careful examination that they are getting what they order.

Walter Baker \& Co.'s cocoa and chocolate preparations are absolutely pure, free from coloring matter, chemical solvents, or adulterants of any kind, and are therefore in full conformity to the requirements of all National and State Pure Food Laws.

Walter Baker \& Co.'s Registered Guarantee Under National Pure Food Laws Is Serial No. 90. 
II.

THE COCOA TREE AND ITS FRUIT.

\section{(" Theobroma Cacao.")}

THE term " cocoa " is a corruption of " cacao," but is almost universally used in English-speaking countries. The cacao tree belongs to the natural order of Sterculiacex, - a family of about $4^{I}$ genera and $52 \mathrm{I}$ species, inhabiting the warmer regions of the world. None of them grow naturally in our climate or in Europe, and, except-

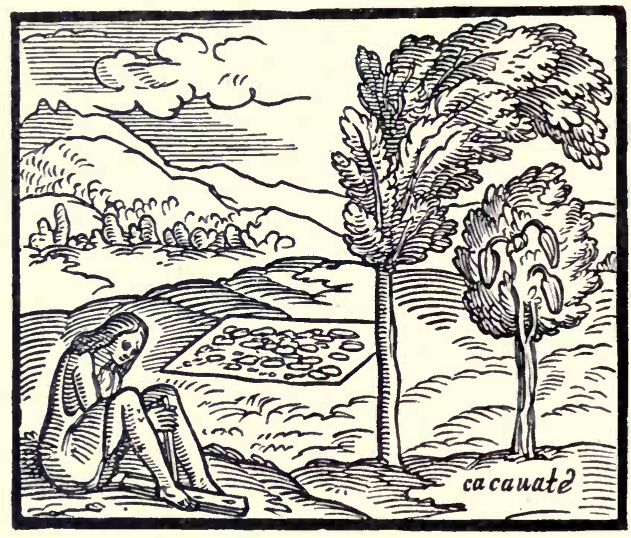

ing the little yellow-flowered Mahernia, they are very seldom seen in our conservatories.

The first references to the tree and its products are found in the accounts of the explorers and conquerors who followed Columbus. Their descriptions are remarkably accurate in all essential particulars. One of the earliest, if not indeed the very earliest, delineations of the tree is in a rare volume by Bontekoe. ${ }^{1}$ The engraving, which is here

\footnotetext{
1 The figure in the left of the foreground is said by Bontekoe to represent the native method of procuring fire by rapidly twirling a pointed stick in a groove of a piece of wood placed on the ground.
} 
reproduced, represents it with its comparatively large fruits or pods. borne on the main stem. This might be thought at first to be an error of the artist, but it is in fact a rude expression of one of the most remarkable peculiarities of the plant. As will be shown presently, when a fuller description is given, the fruits are, as a rule, formed on the older parts. The engraving shows that the cocoa tree is sheltered by a larger tree of some other kind near it. This practise of planting a sheltering tree to shade the young cocoa tree for a time is

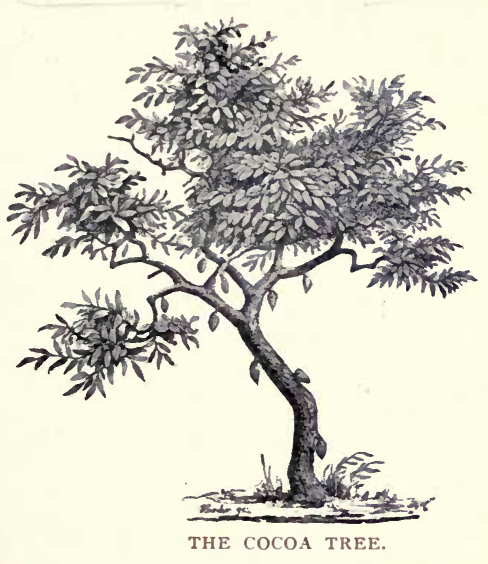
still kept up wherever the plant is successfully cultivated. It is certainly interesting that this point in cultivation, which might easily have been thought to be accidental or local, was delineated more than three centuries ago.

The seeds of the tree are borne in pods, which are irregular and angular in shape, much like some forms of cucumbers, but more pointed at the lower extremity, and more distinctly grooved. These pods measure in length nine inches to a foot, or even more, and about half as much in diameter. The color, when young, is green, becoming later dark yellow or yellowish brown. The rind is thick and tough. The pods are filled with closely packed "beans," or seeds, embedded in a mass of cellular tissue, sometimes of pleasant subacid taste. The seeds are about as large as ordinary almonds, whitish when fresh, and of a disagreeable bitter taste. When dried they become brown.

The fruits are about four months in ripening; but they appear and mature the whole year through. In point of fact, however, there are 
chief harvests, usually in early spring, but this is different for different countries.

As a great many erroneous statements have been made in regard to the average yield of cocoa plantations, from which we draw our supplies of crude cocoa, we have been at some pains to procure accurate information on that point for a period of five years.

Taking twelve cocoa estates in Surinam, containing I,354 hectares, or 3,385 acres, the crop during the years 1897 to I9OI inclusive amounted to $3,672,283$ kilos, or $8,079,023$ pounds. The crops varied for the different years from $1,263,426$ pounds to $2,174,639$ pounds. The average yield per acre per year was $477^{3: 4100}$ pounds. On the basis of 200 trees to the acre this would show an average yield of about $2 \frac{1}{3}$ pounds to a tree. By actual count of seven pods taken with-

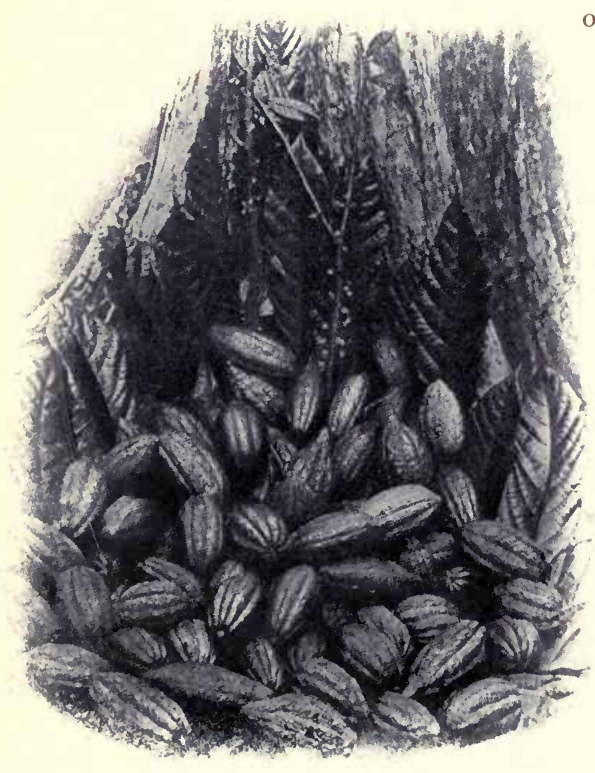

COCOA PODS. out selection it was found that the average number of beans in a pod was 38 .

In an essay (1902) on the cultivation of cacao, for the use of planters in the Philippines, Mr. Wm. S. Lyon, in charge of Seed and Plant Introduction, says :

“ In Camerouns, Dr. Preuss, a close and welltrained observer, gives the mean annual yield of trees of full bearing age at 4.4 pounds.

" Mr. Rousselot places the yield on the French Congo at the same figure. 
In the Caroline Islands it reaches 5 pounds, and in Surinam, according to M. Nichols, the average at maturity is $61 \frac{2}{2}$ pounds. ${ }^{1}$ In Mindanao, I have been told, but do not vouch for the report, of more than ten 'catties' (about $121 \% 2$ pounds) taken in one year from a single tree; , and, as there are well-authenticated instances of record, of single trees
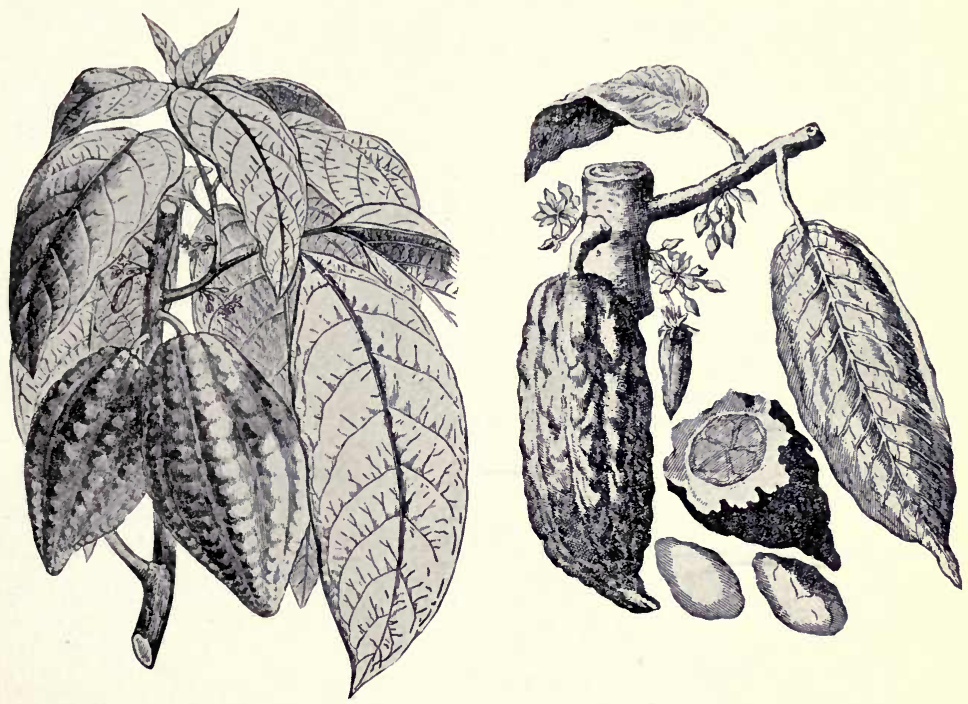

PODS AND LEAVES.

having yielded as much as 30 pounds, I am not prepared to altogether discredit the Mindanao story."

The following statements in relation to the cultivation of the cocoa tree and the curing of the fruit are taken from a report made in 1899 by the United States Consul General at Guayaquil, who obtained his information largely from the Secretary of the Guayaquil Chamber of Commerce.

1 This statement does not accord with the best information we have been able to obtain, namely, that the average yield does not exceed $2 / 3$ pounds to a tree. 
“Cacao is planted from fresh seed. Four or five are put in each hole, which are 5 yards apart, in Formerly they were 2 or 3 yards apart, perience has shown that this method does not give the plant sufficient air, light, and nourishment.

“The preparation of land for a cacao plantation consists in clearing small trees, underbrush, and weeds, the large umbrageous trees. The the trees is planted in corn, arrowthe latter in abundance, with the affording shade to the delicate ducing an immediate income. until the fifth or sixth year, reached a height of 8 or bear fruit, and enters ity. Then auxiliary ground is left trees, which gen50 yards. The palo prieto,

"In the sionally, quickthe

\section{.}

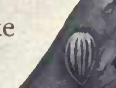

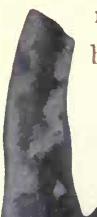
row $\mathrm{s}$. rows.
but exit of but leaving space between root, or plantains, double object of cacao plant and proThese crops are grown when the cacao has 9 feet, commences to upon a stage of perfect vitalcrops cease to be planted and the clear, save for the umbrageous erally stand at intervals of 40 or trees usually selected are the guabo, or guachepeli.

first few years, the plant is pruned occain order that it may 'run to fruit' more ly. Manures have never been used, even where ground has been cultivated for over a century, and no irrigation is practised. The sediment spread over the land by the rains during the rainy season and the decaying vegetation appear to afford sufficient nutriment. In some haciendas, however, the proprietors pile up leaves and other vegetable matter found in the vicinity of the tree at its foot, and 
also rub down the bark with coarse cloths to destroy the adhering parasites.

"The enemies of the cacao tree are the ardillas, the monkeys, many species of small birds which attack the pod, and various parasites, all but two of which are as yet unclassified. These two are the 'mosquilla' and 'mancha.' Continued vigilance protects the fruit from the parrots, animals, etc., but little has been done to extirpate the parasites of the trunk.

"In the sixth or seventh year, the tree commences to bear, but the pods at this time are very small and scarcely repay the effort to gather them. In the tenth year, the tree reaches full maturity. It then produces on an average I pound of dry cocoa of good quality. There are many trees which produce more, especially those which are isolated, some of which have yielded at one picking as much as 7 or 8 pounds. In the province of Oro (Machala), $11 \frac{2}{2}$ to 2 pounds per tree is the estimated yield. The tree is in bloom during the entire year, but most of the blossoms fall before fructification, which occurs twice a year, the time varying with the locality.

"The cacao tree grows to a height of 20 or 30 feet; its leaves are evergreen and lanceolated in form; the base of the main trunk attains a thickness of 8 to ro inches; the bark is hard and of greenish coffee color. The blossom is very small, pinkish white, and waxlike in appearance. It grows directly out of the main trunk and branches. If it fructifies, the petals fall off, and from the stamens, in the course of from fifty to seventy days, an oblong pod is developed. This pod is of golden color, and contains some twenty to thirty-five grains of cacao, enveloped in a gummy liquid, which coagulates on exposure to air. The outer rind of this pod is dark or golden yellow in color and very hard, a sharp instrument being necessary to cut it open. Its size varies, according to the kind of cacao, from 8 to 15 inches long by from 2 to 6 inches thick. The outer rind is marked by longitudinal furrows, more or less pronounced, which indicate the interior arrange- 
ment of the seeds. Both the outer rind and the gummy contents of the pod are porous and blacken in color as soon as picked, and in Ecuador are of use only to fertilize the soil upon which they are cast.

"As soon as the pods begin to ripen, they are removed with pruning knives, very sharp, and attached to the ends of long poles, which are

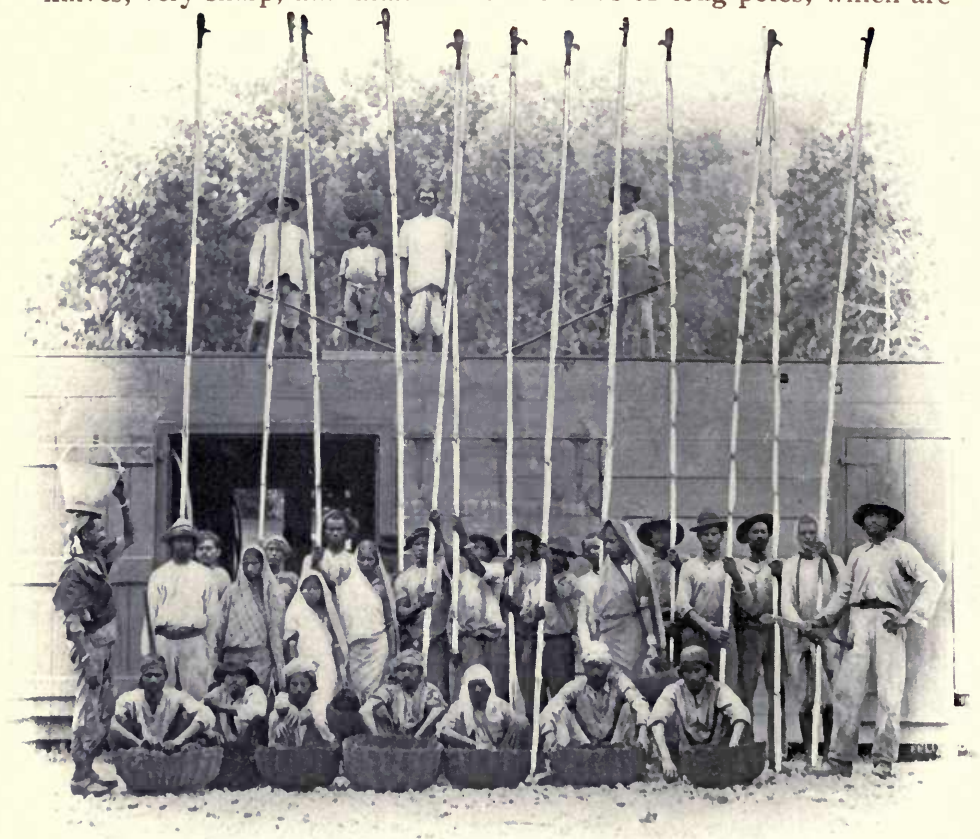

GROTP OF NATIVE COCOA PICKERS.

lengthened by joints as often as required. As the twigs are very tough the blow with this instrument must be strong and well aimed, and the laborers must be experienced on account of the particular skill that is required and the fatigue that attends handling heavy poles sometimes 30 feet long, with the face continually upturned. Wherever they can 
be reached, the pods are cut off with a machete. They are heaped in piles by one set of laborers, while another cuts them open and extracts the contents. A sharp pruning knife is used, and the seeds are often damaged through carelessness. For extracting the gummy substance and the seeds, an implement made of a beef rib is used.

"The drying is done on open platforms made of split bamboo and palms, where the cacao is exposed to the sun during three or four days, and, in order that it may dry uniformly and well, laborers are employed to tread it out with bare feet. If not well dried, the bean is apt to ferment, and if excessively dried it shrinks and, finally, turns black. The driers are provided with covers for protection against rain."

The different methods of fermentation are not described here. The prime object of the sweating or fermentation appears to be to change the inside portion of the bean by absorbing into it products obtained from the fermenting and decomposing pulp, and where this is not accomplished by any of the methods, the bean is classed as unfermented, and the product is of lower value.

The seeds are brought into the market in their crude state, as almond-shaped " beans," which differ in color and somewhat in texture. It is not uncommon to find the external surface more or less covered with a thin, irregular layer of attached earth, but this is almost wholly rubbed off during transportation. Upon the color of shell and kernel, the relative brittleness, the flavor, and the odor depend the market value of the seeds.

The dried seeds have a papery, brittle shell, which is very smooth on the inside, but which on the outside exhibits, under the microscope, a few short hairs and round excrescences. But these are mostly lost by the rough handling and by the attrition of the seeds with one another during transportation. The kernel consists of two large cotyledons or seed-leaves, reddish gray or reddish brown, with a shining, oily surface, the whole crushing rather easily into a loose mass of fragments. The kernel, when dry, has a minute, tough, almost stony 
radicle, which separates easily from the cotyledons. Microscopic examination shows that the cells of the seed-leaves contain albumen, oily matters, - sometimes in a crystalline condition, - crystals of an entirely different shape, starch, coloring substances in special recep-

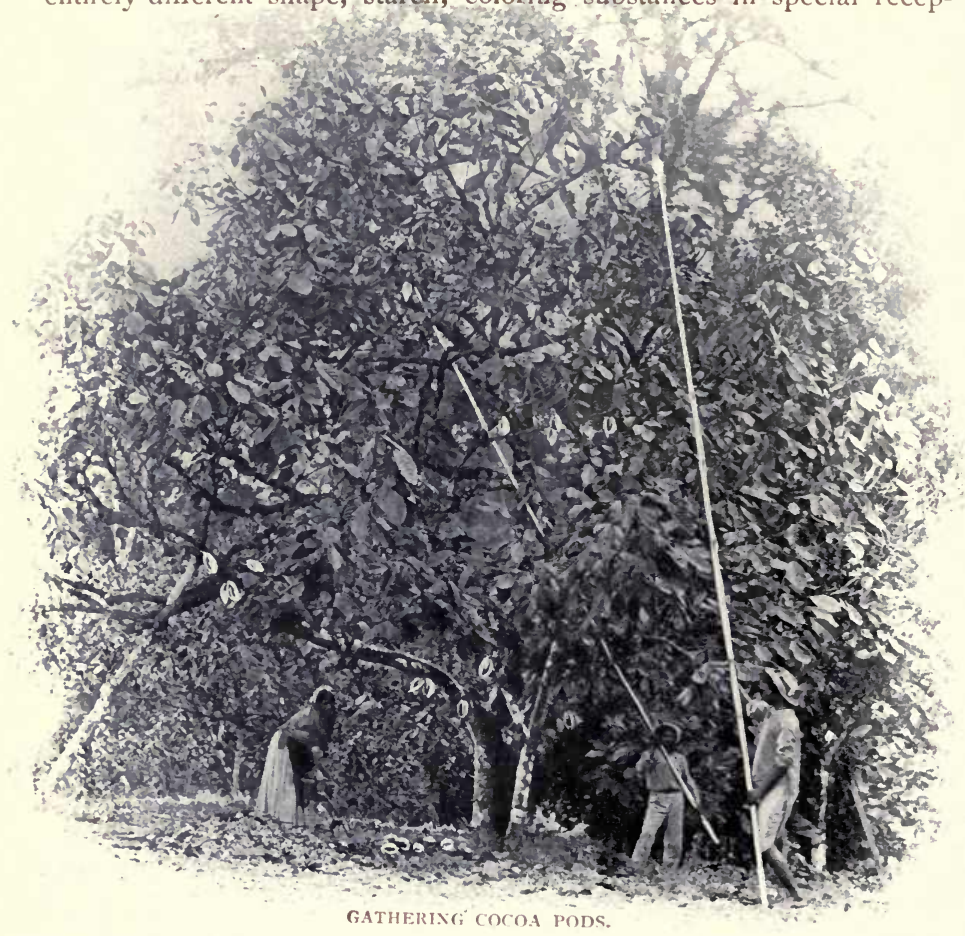

tacles known as pigment cells, and ducts with spiral markings. The starch grains do not have any very characteristic form or markings ; they are generally spherical and simple. The only peculiarity worth mentioning is the relative slowness with which they are acted upon by hot water and by iodine. The coloring substances are mainly of a 
carmine or violet color, and are distinguished by the change of shade when an alkali is added, becoming thereby darker.

These are the only structural elements which a pure powder or paste of chocolate should show under the microscope. Any other substances must be recognized as accidental or intentional additions.

All seeds of whatever kind contain, as a part of their substance, the matter of which cell walls are made, namely, cellulose. The percentage difters in different seeds, in those of the chocolate plant being about three in the hundred. Cellulose has the same chemical composition as starch, but its physical properties are not the same as those of starch; among these may $k e$ mentioned its entire insolubility in boiling water, whereas starch readily dissolves.

Starch forms, on an average, 8 to io per cent. of chocolate seeds. It consists of minute spherical grains, not distinguishable from that found in many other kinds of seeds. Traces of gum and of other allied bodies are also present in the seeds.

Albuminoids, or substances resembling, in a general way, the albumen of egg, occur in chocolate seeds as they do in other seeds, and in a somewhat higher amount than in certain other cases in which seeds are used as food. The percentage ranges from about I 5 to 20 , depending on the variety. These albuminoids are compounds of nitrogen, and are extremely nutritious. In the seeds they occur in a readily assimilable form, fit for digestion.

Cacao red occurs as a coloring matter in small amount. It is rendered dark by alkalies.

Theobromine, the active principle of the cocoa bean, constitutes less than I per cent. of the weight of the seeds, but it varies greatly in amount in different seeds, ranging from $3 \% / 100$ of I per cent. in some to a trifle over I per cent. in others.

The ash left, on completely burning cocoa beans, is not far from 4 per cent. Its composition is substantially that of the ash of seeds of other plants. 
Cocoa butter, or oil, constitutes not far from 50 per cent. of good cocoa beans. The oil is remarkable for its freedom from rancidity and its very bland character. Its uses are innumerable.

The following averages of many analyses by leading authorities may be of interest:-

\section{UNROASTED.}

Moisture . . . . . . . . 7.II

Oil . . . . . . . . 51.78

Theobromine. . . . . . . . .35

Starch . . . . . . . . 5.78

Celluiose . . . . . . . . 3. 3

Other carbohydrates, glucosides, etc. 10.05

Protein matters . . . . . . . . $15.6 \mathrm{I}$

Ash . . . . . . . . . . 360

\section{ROASTED.}

Moisture . . . . . . . . $6.5 \mathrm{r}$

Oil . . . . . . . . . . 49.24

Theobromine . . . . . . . . 43

Starch . . . . . . . . . 10.43

Cellulose . . . . . . . . . $3 \cdot 1$

Other carbohydrates, glucosides, etc. $\quad 7.78$

Protein matters . . . . . . . . 18.33

Ash . . . . . . . . . .. 3.92

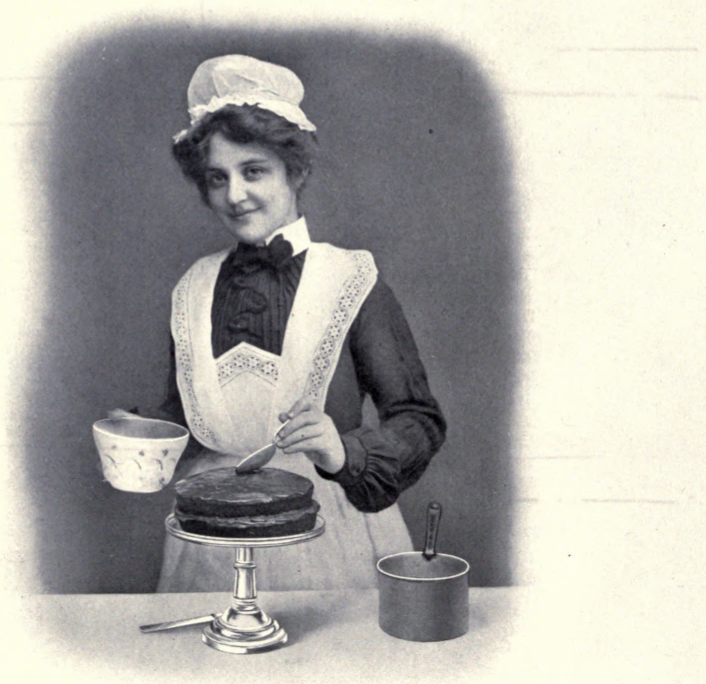




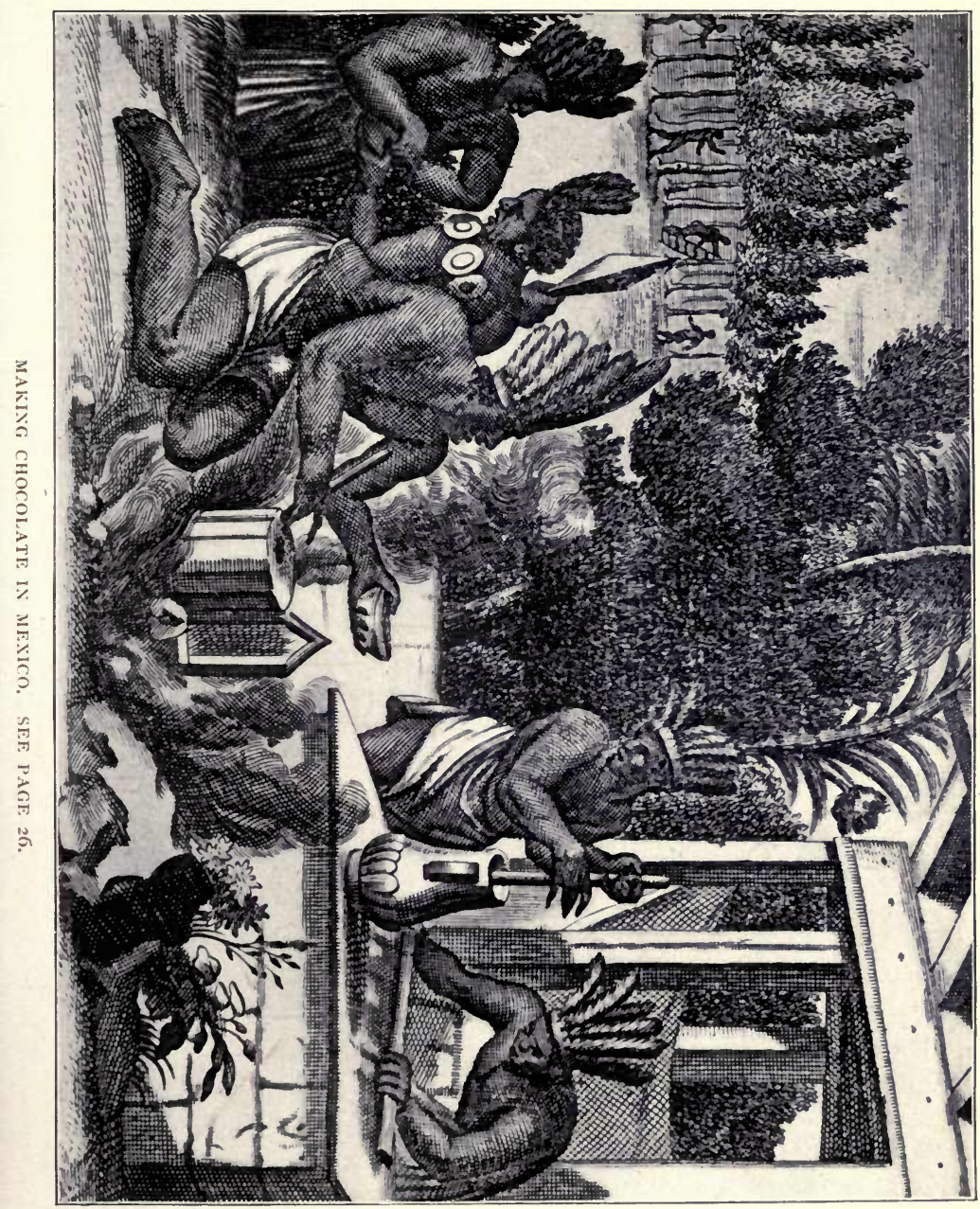




\section{III.}

\section{EARLY USE OF COCOA AND CHOCOLATE.}

7 HE name "chocolate" is nearly the same in most European languages, and is taken from the Mexican name of the drink, "chocolatl," or "cacahuatl." Atl is common enough in Mexican words, and is known to signify water. What the first part of the word means is not so clear. A French writer says it signifies noise, and that the drink was so named because it was beaten to a froth before being drunk.

The Spaniards found chocolate in common use among the Mexicans at the time of the invasion under Cortez, in $\mathrm{I}_{5} \mathrm{I} 9$, and it was introduced into Spain immediately after. The Mexicans not only used chocolate as a staple article of food, but they used the seeds of the cacao tree as a medium of exchange. An early writer says: "In certain provinces called Guatimala and Soconusco there is growing a great store of cacao, which is a berry like unto an almond. It is the best merchandise that is in all the Indies. The Indians make drink of it, and in like manner meat to eat. It goeth currently for money in any market, or fair, and may buy flesh, fish, bread or cheese, or other things."

In the " True History of the Conquest of Mexico," by Bernal Diaz, an officer under Cortez, it is related that " from time to time a liquor prepared from cocoa and of a stimulating or corroborative quality, as we are told, was presented to Montezuma in a golden cup. We could not at the time see if he drank it or not, but I observed a number of jars - above fifty - brought in and filled with foaming chocolate."

Thomas Gage, in his “ New Survey of the West Indies," first published in 1648 , gives the following interesting account of the Spanish 
and Indian ways of making and drinking chocolate some two hundred and fifty years ago: -

"Now, for the making or compounding of this drink, I shall set down here the method. The cacao and the other ingredients must be

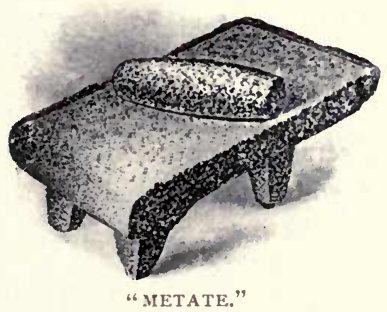
beaten in a mortar of stone, or (as the Indians use) ground upon a broad stone, which they call Mctate, and is only made for that use. But first the ingredients are all to be dried, except the Achiotte (annotto), with care that they be beaten to powder, keeping them still in stirring that they be not burnt, or become black; for if they be overdried they will be bitter and lose their virtue. The cinnamon and the long red pepper are to be first beaten with the anniseed, and then the cacao, which must be beaten by little and little till it be all powdered, and in the beating it must be turned round that it may mix the better. Every one of these ingredients must be beaten by itself, and then all be put into the vessel where the cacao is, which you must stir together with a spoon, and then take out that paste, and put it into the mortar, under which there must be a little fire, after the confection is made; but if more fire be put under than will only warm it, then the unctuous part will dry away. The Achiotte also must be put in in the beating, that it may the better take the colour. All the ingredients must be searced, save only the cacao, and if from the cacao the dry shell be taken, it will be the better. When it is well beaten

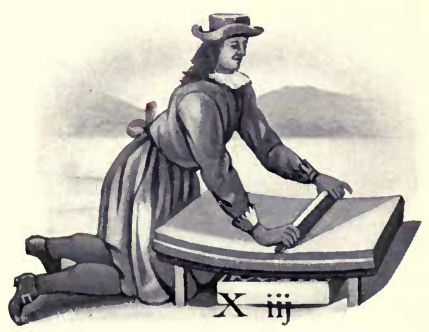

CHOCOLATE-GRINDING IN THE SEVENTEENTH CENTURY.

From an carly engraving. and incorporated (which will be known by the shortnesse of it) then with a spoon (so in the Indias is used) is taken up some of the paste, 
which will be almost liquid, and made into tablets, or else without a spoon put into boxes, and when it is cold it will be hard.

“ Those that make it into tablets put a spoonful of the paste upon a piece of paper (the Indians put it upon the leaf of a plaintain tree), where, being put into the shade (for in the sun it melts and dissolves), it grows hard; and then bowing the paper or leaf, the tablet fals off by reason of the fatnesse of the paste. But if it be put into anything of earth or wood, it stickes fast, and will not come off but with scraping or breaking. The manner of drinking it is divers; the one (being the way most used in Mexico) is to take it hot with Atolle, dissolving a tablet in hot water, and stirring and beating it in the cup, when it is to be drunk, with a Molinet, and when it is well stirred to a scumme or froth, then to fill the cup with hot Atolle, and so drink it sup by sup. Another way is that the chocolate, being dissolved with cold water and stirred with the Molinet, and the scumme being taken off and put into another vessel, the remainder be set upon the fire, with as much sugar as will sweeten it, and when it is warme, then to powre it upon the scumme which was taken off before, and
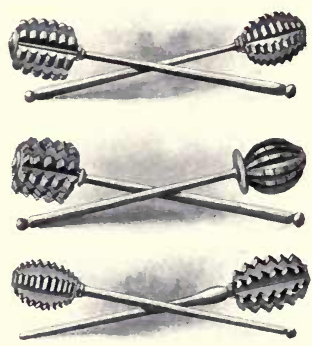

- MOLIXETS." so to drink it. But the most ordinary way is to warme the water very hot, and then to powre out half the cup full that you mean to drink; and to put into it a tablet or two, or as much as will thicken reasonably the water, and then grinde it well with the Molinet, and when it is well ground and risen to a scumme, to fill the cup with hot water, and so drink it by sups (having sweetened it with sugar), and to eat it with a little conserve or maple bred, steeped into the chocolatte.

"Besides these ways there is another way (which is much used in the Island of Santo Domingo), which is to put the chocolatte into a pipkin with a little water, and to let it boyle well till it be dissolved, and then to put in sufficient water and sugar according to the quantity of 
the chocolatte, and then to boyle it again untill there comes an oily scumme upon it, and then to drink it.

" There is another way yet to drink chocolatte, which is cold, which the Indians use at feasts to refresh themselves, and it is made after this manner: The chocolatte (which is made with none, or very few, ingredients) being dissolved in cold water with the Molinet, they take off the scumme or crassy part, which riseth in great quantity, especially when the cacao is older and more putrefied. The scumme they lay aside in a little dish by itself, and then put sugar into that part from whence was taken the scumme, and then powre it from on high into the scumme, and so drink it cold. And this drink is so cold that it agreeth not with all men's stomachs; for by experience it hath been found that it doth hurt by causing pains in the stomach, especially to women.

" The third way of taking it is the most used, and thus certainly it doth no hurt, neither know I why it may not be used as well in England as in other parts, both hot and cold; for where it is so much used, the most, if not all, as well in the Indias as in Spain, Italy, Flanders (which is a cold countrey), find that it agreeth well with them. True it is, it is used more in the Indias than in the European parts, because there the stomachs are more apt to faint than here, and a cup of chocolatte well confectioned comforts and strengthens the stomach. For myself I must say, I used it twelve years constantly, drinking one cup in the morning, another yet before dinner between nine or ten of the clock; another within an hour or two after dinner, and another between four and five in the afternoon; and when I was purposed to sit up late to study, I would take another cup about seven or eight at night, which would keep me waking till about midnight. And if by chance I did neglect any of these accustomed houres, I presently found my stomach fainty. And with this custome I lived twelve years in those parts healthy, without any obstructions, or oppilations, not knowing what either ague or feaver was." 
Another writer of the seventeenth century ${ }^{1}$ describing the various products of the New World, says :-

" But much more beneficial is the Cacao, with which Fruit New Spain drives a great Trade; nay, serves for Coin'd Money. When they deliver a Parcel of Cacao, they tell them by five, thirty and a hundred. Their Charity to the Poor never exceeds above one CacaoNut. The Trees on which this Fruit grows are divided into four sorts, differing in bigness and shape: all of them are very tender, for they will not only grow in no place, but on their usual Ground, but cannot endure the cold Nights Storms, or excesses of Heat; wherefore the Cacao-Trees which grow out of the Fruit that falls off, come to no perfection, except in shady and warm Valleys; which is also the reason why the Planters of New Spain plant the great Leafy Tree Cacaoquanthly (that is, The Mother of the Cacao's) near the CacaoTree, that it may the better grow under the Shadow thereof; in which manner whole Woods are planted: In the second year it bears Fruit, which is first ripe in January, and again in the midst of Summer. Amongst the four sorts the chiefest is Quathuitl, of an indifferent heighth, and full of sharp-pointed Leaves, which are fast to the Boughs without Stalks, and bears a great Flower of a yellowish colour, which falling off, leaves long, tough and hairy Threds behind them, out of which grows the Cacavently, a Fruit which is oval, heavy like a Melon, of a Saffron-colour, of a fat and thick Juice, a bitterish, yet pleasant taste, and very cooling; being dry'd in the Sun it is thereby made fit to keep : it is likewise highly esteem'd, because the Chocolate is made of the same. Before the Spaniards made themselves Masters of Mexico, no other Drink was esteem'd but that of the Cacao; none caring for Wine, notwithstanding the Soil produces Vines every where in great abundance of it self. But besides the Quathuitl, New Spain hath three other sorts of Cacao-Trees, viz. Mecanal, pleasant to behold

\footnotetext{
1 America: Being the Latest, and Most Accurate Description of the New World. By Arnoldus Montanus.
Collected by John Ogilby, 167i.
} 


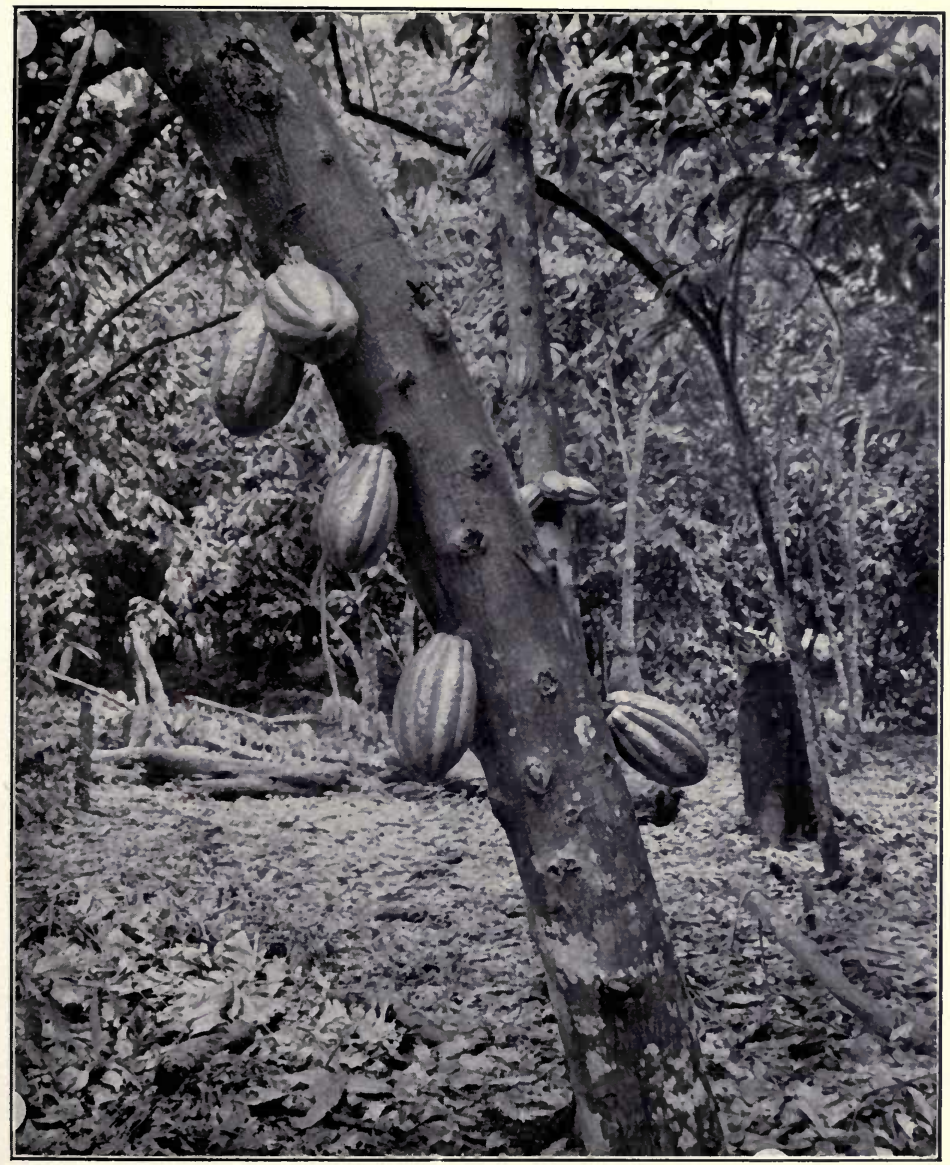

From stereograph, copyright, 1906, by Underwood \& Underwood, New lork.

CACAO TREE WITH POIS 4 MONTHS OLD GROWING FROM TRUNK.

La Clementina hacienda, Ecuador. The scars on trunk show where pods have grown in former seasons 
for its heighth, large Leaves and Fruit: the next is the Xochucaual, which is less than the former; and lastly, the least sort, which is call'd Halcacahual. The Fruit of these four sorts of Trees, though differing in shape, yet is all one in power and operation."

M. Ferdinand Denis, in "La Legende du Cacahuatl," makes the following interesting statement in regard to the preparation of choco-

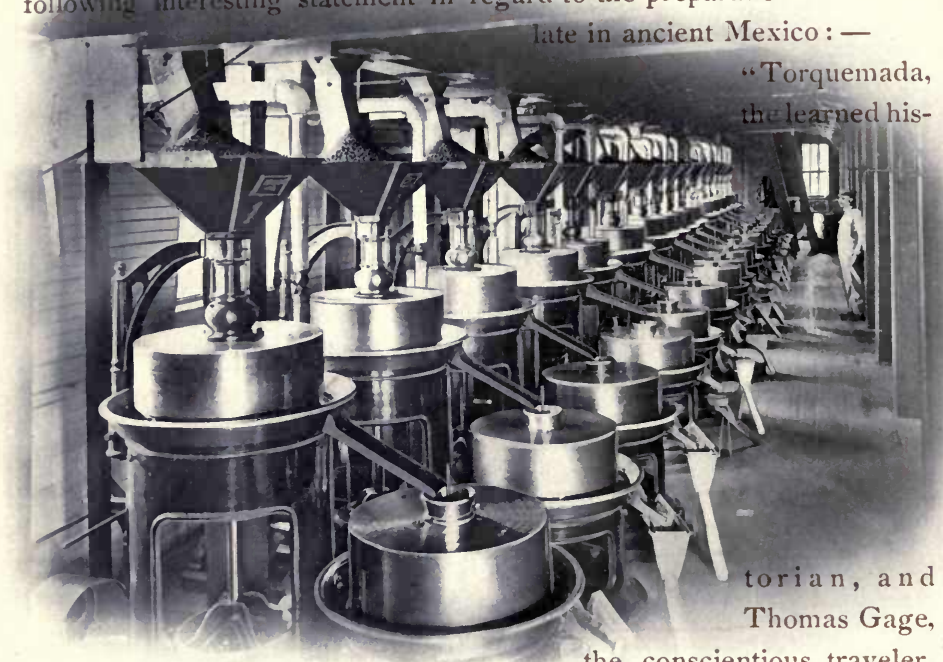

GRINDING ROOM IN ONE OF WALTER BAKER \& CO.'S MILLS. agree in telling us that hot chocolate was an invention

of the Castilians. The first of these writers, who lived at the end of the sixteenth century, says so positively; in his time it had been used for only a few years.

"Would you know now what chocolate was when the learned Antonio Colmenero de Ledesma ${ }^{1}$ gave his receipt ? I copy it for you here : -

1 Colmenero de Ledesma (Antonio) Chocolata Inda Opsisculum de qualitate \& Natura Chocolaex, $12 \mathrm{mo}$ Notimbergx, 1644 . 
“، T Take a hundred cacao kernels, two heads of Chili or long peppers, a handful of anise or orjevala, and two of mesachusil or vanilla, - or, instead, six Alexandria roses, powdered, - two drachms of cinnamon, a dozen almonds, and as many hazel-nuts, a half pound of white sugar, and annotto enough to color it, and you have the king of chocolates."

The Spaniards thus early acquired a knowledge of the fruit and of the manner of preparing it, which they kept secret for many years,

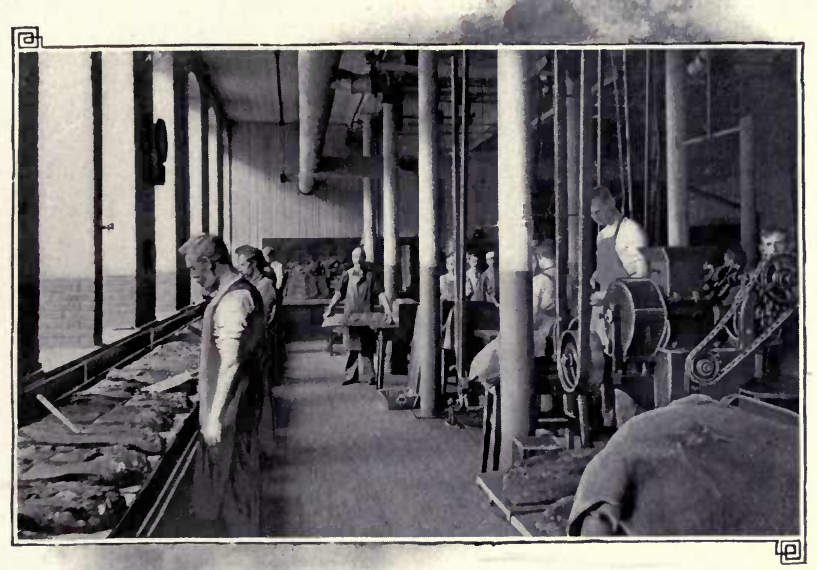

A MOLDING ROOM IN WALTER BAKER \& CO'S MILLS.

selling it very profitably as "chocollat" to the wealthy and luxurious classes of Europe.

Says Brillat-Savarin, in his famous " Physiologie du Gout," “Chocolate came over the mountains [from Spain to France] with Anne of Austria, daughter of Philip III., and queen of Louis XIII. The Spanish monks also spread the knowledge of it by the presents they made to their brothers in France. It is well known that Linnæus called the fruit of the cocoa tree theobroma, 'food for the gods.' The cause of this emphatic qualification has been sought, and attributed by 
some to the fact that he was extravagantly fond of chocolate: by others to his desire to please his confessor; and by others to his gallantry, a queen having first introduced it into France.

“The Spanish ladies of the New World, it is said, carried their love for chocolate to such a degree that, not content with partaking of it several times a day, they had it sometimes carried after them to church. This faroring of the senses often drew upon them the censures of the bishop; but the Reverend Father Escobar, whose metaphysics were as

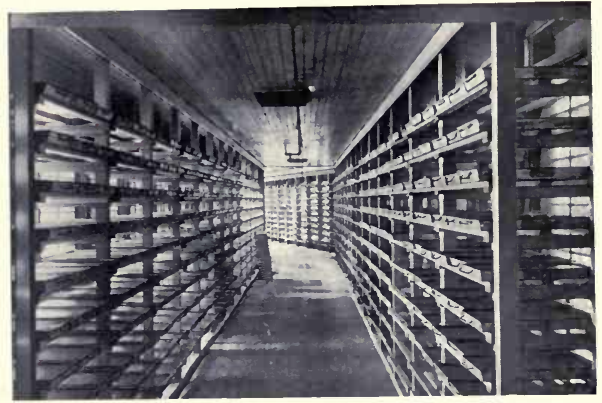

COOLING ROOM, WALTER BAKER \& CO'S MILLS. subtle as his morality was accommodating, declared, formally, that a fast was not broken by chocolate prepared with water; thus wiredrawing, in favor of his penitents, the ancient adage, 'Liquidum non frangit jejunium."

Chocolate appears to have been highly valued as a remedial agent by the leading physicians of that day. Christoph Ludwig Hotfmann wrote a treatise entitled "Potus Chocolate," in which he recommended it in many diseases, and instanced the case of Cardinal Richelieu, who, he stated, was cured of general atrophy by its use.

The earliest intimation of the introduction of cocoa into England is found in an announcemeist in the Public Adzertiser of Tuesday, June I6, I657 (more than a hundred and thirty years after its introduction into Spain), stating that “In Bishopsgate Street, in Queen's Head Alley, at a Frenchman's house, is an excellent West India drink, called chocolate, to be sold, where you may have it ready at any time; and also unmade, at reasonable rates." 
Two years later, in the Mcrcurius Politicus for June, I659, it is stated that “ Chocolate, an excellent West India drink, is sold in Queen's Head Alley, in Bishopsgate Street, by a Frenchman who did formerly sell it in Grace Church Street and Clement's Churchyard, being the first man who did sell it in England ; and its virtues are highly extolled."

A book written in the time of Charles II., entitled "'The Indian Nectar, or a Discourse Concerning Chocolate, etc.," says the best kind can be purchased of one Mortimer, " an honest though poor man, living in East Smithfield," for 6s. 8d. per pound, and commoner sorts for about half that price.

About the beginning of the eighteenth century chocolate had become an exceedingly fashionable beverage, and the cocoa tree was a favorite sign and name for places of public refreshment. Cocoa and chocolate are frequently mentioned in contemporary literature; and among others Pope, in his "Rape of the Lock," alludes to it ; the negligent spirit, fixed liked Ixion, -

"In fumes of burning chocolate shall glow, And tremble at the sea that froths below.

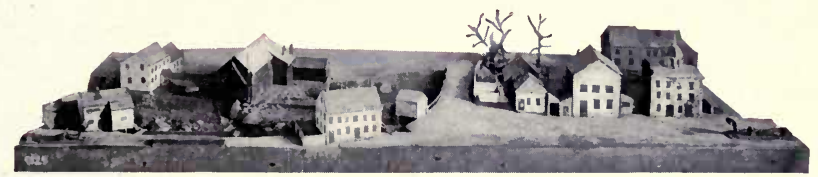

MILTON LOWER MILLS IN I822 - FROM MODEL. WALTER HAKEIR \& CO.'S MILL ON THE RIGHT.

Chocolate was first manufactured in this country in 1765 , in a mill on the Dorchester side of the Neponset River, at a point long known as Milton Lower Mills. Fifteen years later the plant came into the possession of Dr. James Baker, and the small beginning then made of a new industry has developed into the world-famous manufacturing establishment known as Walter Baker \& Co. Ltd., of which some account is given farther on. 
The first notice of the sale of cocoa and chocolate in this country appears in the Boston Gazette and Country Journal of March I2, I 770 , as follows :-

$$
\begin{gathered}
\text { "TO BE SOLD BY } \\
\text { JOHN BAKER }
\end{gathered}
$$

At his Store in Back Street a few Bags of the best Cocoa; also choice Chocolate by the Hundred or Smaller Quantity."

The following from the Essex Gazette, of June 18, I771, contains the first public notice of the manufacture of chocolate:

$$
\text { “AMOS TRASK, }
$$

At his House a little below the Bell-Tavern in

DANVERS,

Makes and sells CHOCOLATE,

which he will warrant to be good, and takes

Cocoa to grind. Those who may please to favour him with their Custom may depend upon being well served, and at a very cheap Rate.”

Two years later the Boston Gazette and Country Journal (April 5. I773) contained the following notice :-

\section{"CHOCOLATE}

TO BE SOLD BY JOSEPH MANN, choice Chocolate made by himself, and Warranted pure, likewise good Cocoa Shells, at his House in Water-Street, next Door to Ebenezer Torrey Baker, at the Sign of the Wheat Sheaff near Oliver's Dock, Boston. - Also Cocoa taken in to Grind: Any gentlemen who will please to favour him with their Custom may depend on having it done with Fidelity and Dispatch." 
Crude cocoa was brought to the American market at that time by the Massachusetts traders, especially the Gloucester fishermen who received it in exchange for the fish and other articles which they shipped to the West Indies and Central and South America; and the direct connection with the producers, thus early established, was maintained until recent years.

In giving an account of the manufactures in Boston, in $1794, \mathrm{~J} . \mathrm{L}$. Bishop, in his " History of American Manufactures," says: "Chocolate had long been made from the large quantities of cocoa obtained in the West India trade, and had been greatly expedited by recent inventions. The chocolate mill of Mr. Welsh, at the North End, could turn out 2,500 lbs. daily."

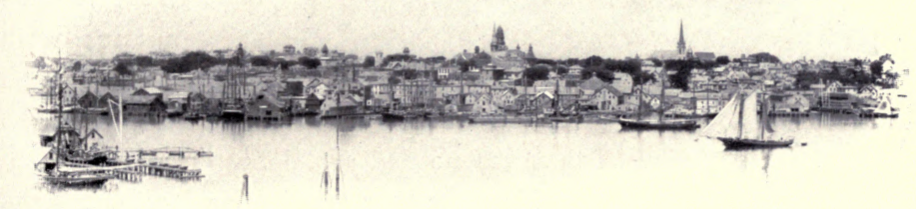


IV.

\section{A PERFECT FOOD.}

DARON VON LIEBIG, one of the best-known writers on dietetics, says :-

"Chocolate is a perfect food, as wholesome as it is delicious, a beneficent restorer of exhausted power; but its quality must be good, and it must be carefully prepared. It is highly nourishing and easily digested, and is fitted to repair wasted strength, preserve health, and

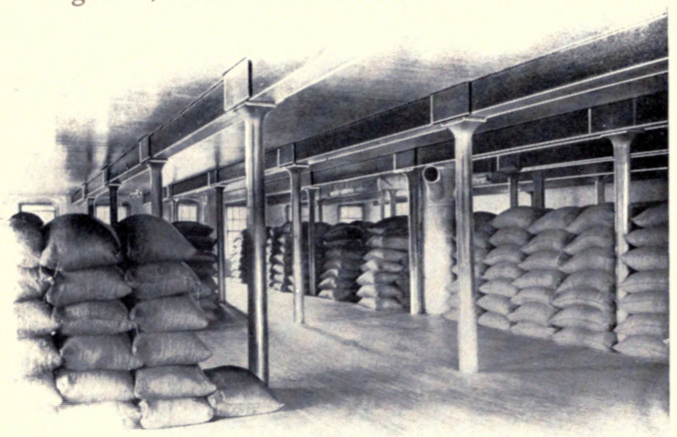

STORAGE OF COCOA BEANS.

prolong life. It agrees with dry temperaments and convalescents; with mothers who nurse their children; with those whose occupations oblige them to undergo severe mental strains; with public speakers, and with all those who give to work a portion of the time needed for sleep. It soothes both stomach and brain, and for this reason, as well as for others, it is the best friend of those engaged in literary pursuits."

Dr. Edward Smith, LL.B., F.R.S., in his valuable work on " Foods," for the International Scientific Series, says :-

" These well-known substances (cocoa and chocolate) are valuable foods, since they are not only allied to tea and coffee as respiratory excitants, but possess a large quantity of fat and other food materials. . . ." 
After giving an analysis of the cocoa bean, he goes on to say: "This substance in its action is less exciting to the nervous system than tea or coffee, and at the same time it contains a much larger proportion of nutritive material. Moreover, its flavor is not lessened by the addition of milk, so that it can be boiled in milk only, and thus produce a most agreeable and nu-

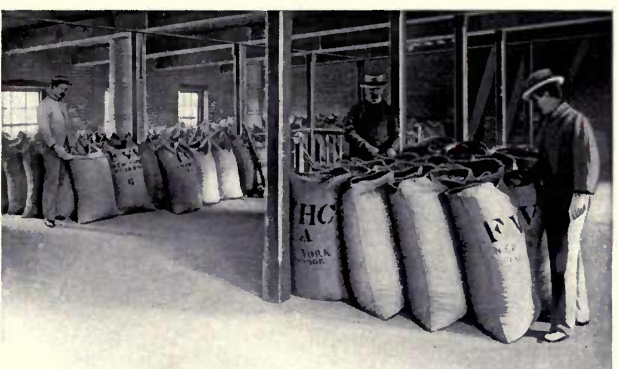
INSPECTION OF BEANS.

tritious food. There are, therefore, many persons, states of system, and circumstances in which its use is to be preferred to either tea or coffee."

Brillat-Savarin, from whose work we have already quoted, says time and experience have shown " that chocolate, carefully prepared, is an article of food as wholesome as it is agreeable; that it is nourishing, easy of digestion, and does not possess those qualities injurious to beauty with which coffee has been reproached; that it is excellently adapted to persons who are obliged to a great concentration of intellect in the toils of the pulpit or the bar, and especially to travelers; that it suits the most feeble stomach; that excellent effects have been produced by it in chronic complaints, and that it is a last resource in affections of the pylorus.

"Some persons complain of being unable to digest chocolate; others, on the contrary, pretend that it has not sufficient nourishment, and that the effect disappears too soon. It is probable that the former have only themselves to blame, and that the chocolate which they use is of bad quality or badly made; for good and well-made chocolate must suit every stomach which retains the slightest digestive power.

"In regard to the others, the remedy is an easy one: they should reenforce their breakfast with a paté, a cutlet, or a kidney; moisten 


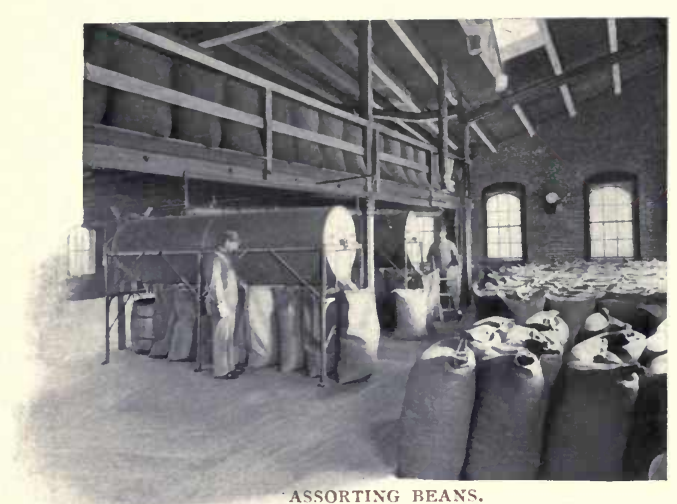

the whole with a good draught of soconusco chocolate, and thank God for a stomach of such superior activity.

"This gives me an opportunity to make an observation whose accuracy may be depended upon.

"After a good, complete, and copious breakfast, if we take in addition a cup of well-made chocolate, digestion will be perfectly accomplished in three hours, and we may dine whenever we like. Out of zeal for science, and by dint of eloquence, I have induced many ladies to try this experiment. They all declared, in the beginning, that it would kill them; but they have all thriven on it, and have not failed to glorify their teacher.

"The people who make constant use of chocolate are the ones who enjoy the most steady health, and are the least subject to a multitude of little ailments which destroy the comfort of life; their plumpness is also more equal. These are two advantages which every one may verify among his own friends, and wherever the practise is in use."

M. Boussingault, a member of the French Institute, in an interesting paper printed in the " $A n$ nales de Physique et du Chimie," says :-

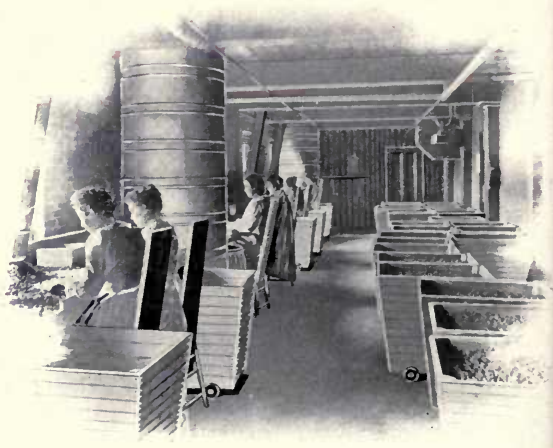

FINAI, PROCESS OF SELECTION. 
"Chocolate contains a very large proportion of nutritive matter in a small volume. In an expedition to a great distance, where it is imperatively necessary to reduce the weight of the rations, chocolate offers undeniable advantages, as I have had

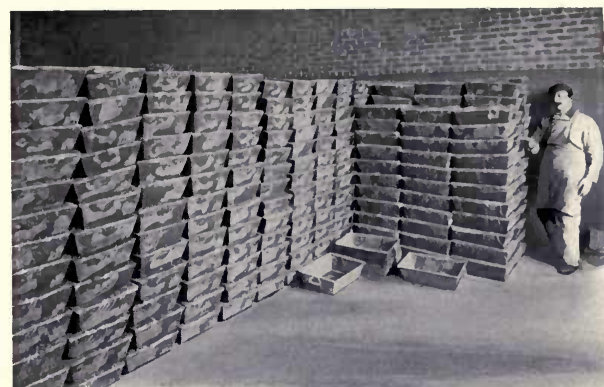

SWEET CHOCOLATE IN STORAGE. frequent occasions to notice. Humboldt recalls what has been said with reason, that in Africa rice, gum, and butter enable men to cross the desert; and he adds that, in the New World, chocolate and corn meal render the plateaus of the Andes and the vast, uninhabited forests accessible to man.

“In Central America, when they organize a river expedition, or traverse the forests, they prepare chocolate for provision with eighty parts of cocoa to twenty of coarse sugar, the composition being as follows :-

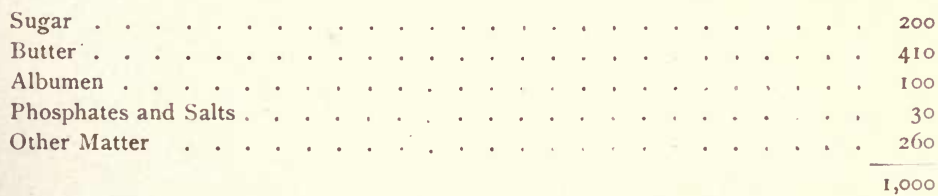

"Each man receives 60 grams (about 2 ounces) of this chocolate per day, in which there are I 2 grams of sugar, 26 of butter, and 6 of albumen. It is a useful addition to the ration formed of beef slightly salted and dried in the air, of rice, of corn biscuit, or of cassava muffins.

"The infusion of tea, maté (Paraguay tea), and coffee are not, of course, to be considered as food. The amount of solid matter in them is very slight, and their effects are due only to their alkaloids. 
"This is not true of chocolate, which is at the same time complete food and an active excitant, since it approaches in composition that model food, milk. In fact we have seen that in cocoa there is legumine and albumen, associated with fat, sugar to sustain respiratory combustion, phosphates, which are the basis of the bones, and - what milk does not have - theobromine and a delicate aroma. Roasted,

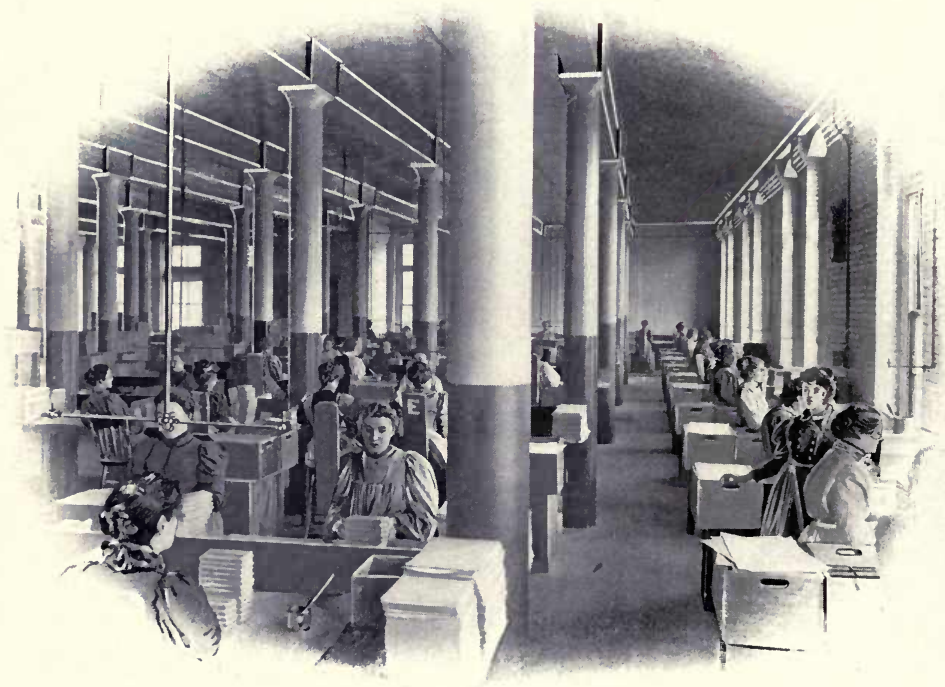

WRAPPING ROOM, BAKER'S CHOCOLATE.

ground, and mixed with sugar, cocoa becomes chocolate, the nutritive properties of which astonished the Spanish soldiers that invaded Mexico.”

Dr. Edmund A. Parkes, F.R.S., in his “ Manual of Practical Hygiene, prepared especially for use in the Medical Service of the Army" (London, 1864), says:- 
"Although the theobromine of cocoa is now known to be identical with theine and caffeine, the composition of cocoa removes it widely from tea and coffee. The quantity of fat varies even in the same sort of cocoa. The ash contains a large quantity of phosphate of potash. The larger quantity of fat makes it a very nourishing article of diet, and it is therefore useful in weak states of the system, and for healthy men under circumstances of great exertion. It has even been compared to milk. In South America cocoa and maize cakes are used by travelers, and the large amount of agreeable nourishment in small bulk

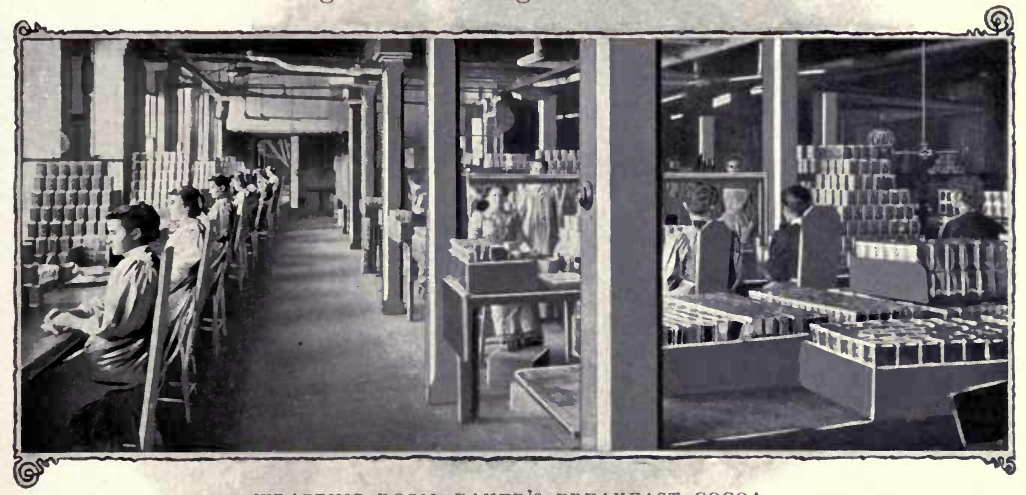

WRAPPING ROOM, BAKER'S BREAKFAST COCOA.

enables several days' supplies to be easily carried. By roasting, the starch is changed into dextrine, the amount of margaric acid increases, and an empyrematic aromatic substance is formed."

François Joseph Victor Broussais, a celebrated physician and member of the French Institute, says :-

" Chocolate of good quality, well made, properly cooked, is one of the best aliments that I have yet found for my patients and for myself. This delicious food calms the fever, nourishes adequately the patient, and tends to restore him to health. I would even add that I attribute many cures of chronic dyspepsia to the regular use of chocolate." 
Christoph Wilhelm Hufeland, the distinguished German physician, says :-

"I recommend good chocolate to nervous, excitable persons; also to the weak, debilitated, and infirm; to children and women. I have obtained excellent results from it in many cases of chronic diseases of the digestive organs."

Dr. Karl Ernest Bock, of Leipsic, author of a "Traite de Pathologie ct de Diagnostic," says : -

"The nervousness and peevishness of our times are chiefly attribu-

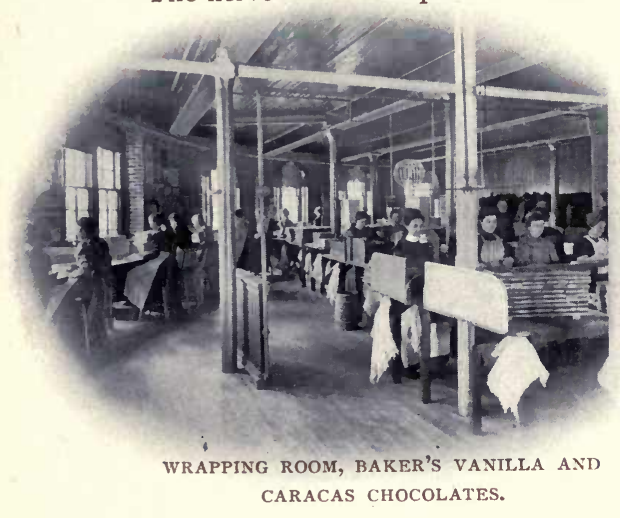

Jean Baptiste Alphonse Chevalier, in his treatise on chocolate, says :-

"Cocoa and chocolate are a complete food; coffee and tea are not food. Cocoa gives one third its weight in starch and one half in cocoa butter ; and, converted into chocolate by the addition of sugar, it realizes the idea of a complete aliment, wholesome and eminently hygienic. The shells of the bean contain the same principles as the kernels, and the extract, obtained by an infusion of the shells in sweetened milk, forms a mixture at once agreeable to the taste and an advantageous substitute for tea and coffee." 
Mme. de Sevigne, in one of her letters to her daughter, says :-

"I took chocolate night before last to digest my dinner, in order to have a good supper. I took some yesterday for nourishment, so as to be able to fast until night. What I consider amusing about chocolate is that it acts according to the wishes of the one who takes it."

It will be observed that Brillat-Savarin corroborates this statement as to the value of chocolate as an aid to digestion.

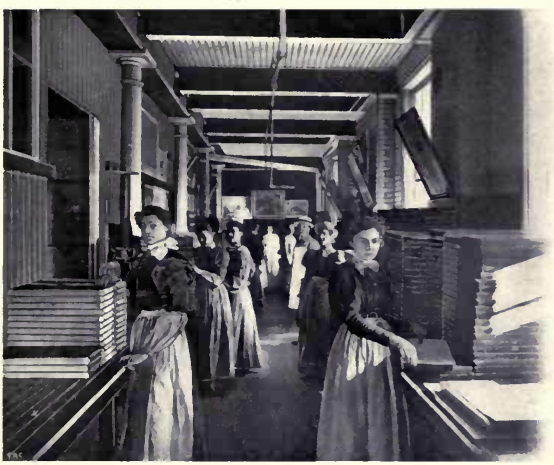

WRAPPING CONFECTIONER'S CHOCOLATE.

"The cocoa bean," says M. Payen, in "Des Substances Alimentaires," "has in its composition more nitrogen than wheat flour, about twenty times as much fatty matter, a considerable proportion of starch, and an agreeable aroma which excites the appetite. We are entirely disposed to admit that this substance contains a remarkable nutritive power. Besides, direct experience has proved this to be the case. In fact, cocoa, closely combined with an equal or two thirds' weight of sugar, forming the article well-known under the name of chocolate, constitutes a food, substantial in all respects, and capable of sustaining the strength in traveling."

And a little farther on, he adds :-

"Cocoa and chocolate, in consequence of their elementary composition, and of the direct or indirect addition of sugar before their consumption, constitute a food, respiratory, or capable of maintaining animal heat, by means of the starch, sugar, gum, and fatty matter which they contain; they are also articles of food favorable to the 
maintenance or development of the adipose secretions, by reason of the fatty matter (cocoa butter) belonging to them; and, finally, they assist in the maintenance and increase of the tissues by means of their congeneric azote substances, which assimilate therewith."

Etienne François Geoffroy, the distinguished French physician and professor of medicine and pharmacy in the College of France, says, in his "Traité de Matière Médicale": -

" The drinking of chocolate, especially of that made with milk, is recommended to persons affected with phthisis or consumption; and,

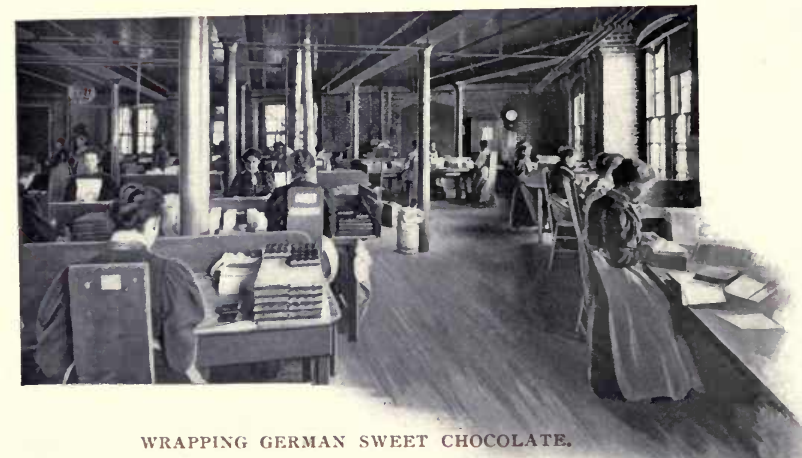

in fact, it supplies a juice which is nourishing, substantial, and smooth, which dcadens the acrimony of the humors; provided, as we have said, that the cocoa is properly roasted, and mixed with a very small quantity of spices."

A French officer who served in the West Indies for a period of fifteen years, during the early part of the last century, wrote, as the result of his personal observations, a treatise on "The Natural History of Chocolate, Being a Distinct and Particular Account of the Cacao Tree, Its Growth and Culture, and the Preparation, Excellent Properties, and Medicinal Virtues of Its Fruit," which received the approbation of the 
Regent of the Faculty of Medicine at Paris, and which was translated and published in London, in I730. After describing the different methods of raising and curing the fruit and preparing it for food (which it is not worth while to reproduce here, as the methods have essentially changed since that time), he goes on to demonstrate, as the result of actual experiment, that chocolate is a substance "very temperate, very nourishing, and of easy digestion; very proper to repair the exhausted

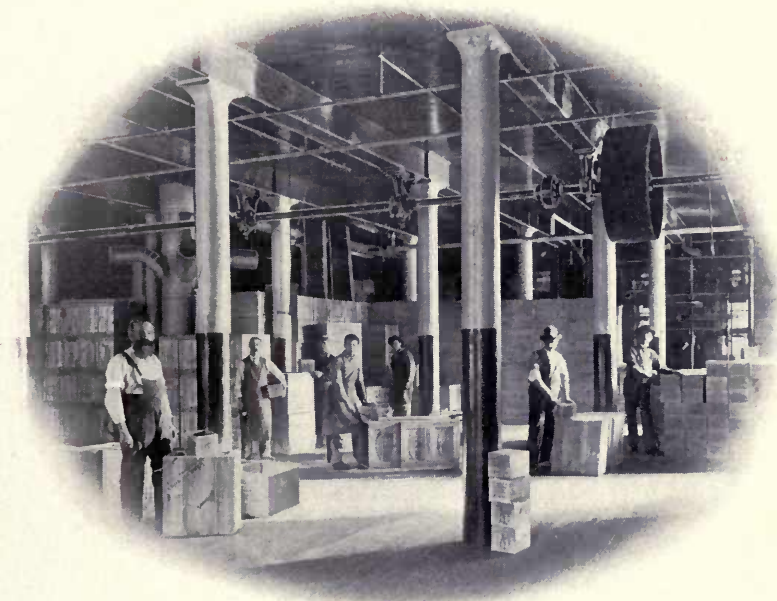

PACKING ROOM, BAKER'S CHOCOLATE.

spirits and decayed strength; and very suitable to preserve the health and prolong the lives of old men. . . .

" There lately died at Martinico a counselor, about a hundred years old, who for thirty years past lived on nothing but chocolate and biscuit. He sometimes, indeed, had a little soup at dinner, but never any fish, flesh, or other victuals. He was, nevertheless, so vigorous and nimble that at fourscore and five he could get on horseback without stirrups. 
" Chocolate is not only proper to prolong the life of aged people, but also of those whose constitution is lean and dry, or weak and cacochymical, or who use violent exercises, or whose employments oblige them to an intense application of mind, which makes them very faintish. To all these it agrees perfectly well, and becomes to them an altering diet."

Dr. Nansen, the famous Arctic explorer, in his book entitled “ The First Crossing of Greenland" (Vol. I., p. 58), speaks of chocolate as an important part of the equipment for such an undertaking. "We generally," he says, "used chocolate in the morning." Referring to tea, coffee, and alcoholic drinks, he says: "Stimulants of this kind, with the exception of chocolate, which is mild in its effect and at the same time nourishing, bring practically no nutritive substance into the body, and the energy which one obtains in anticipation by their use at one moment must be paid for by a corresponding exhaustion at the next."

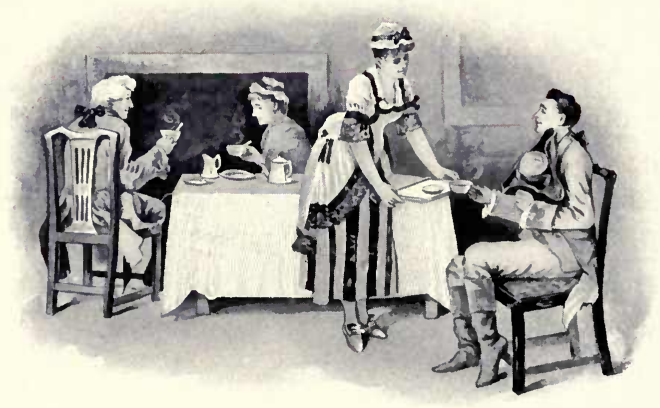




\section{V.}

\section{THE HOUSE OF WALTER BAKER \& CO. LTD.}

.

$\mathrm{T}$ is stated, on what appears to be $\operatorname{good}$ authority, ${ }^{\mathrm{T}}$ that the chocolate mill erected on Neponset River, in the town of Dorchester, Mass., in 1765 , was the first mill of that kind established in the British provinces of North America. It was connected with a sawmill, operated by water-power, and was regarded as a somewhat doubtful experiment. Its establishment was due to the representations made by John Hannan, an Irish immigrant, who had learned the business of chocolate making in England. The new industry prospered in a small way, and on the death of Hannan, in 1780 , Dr. James Baker established the house which has continued under the

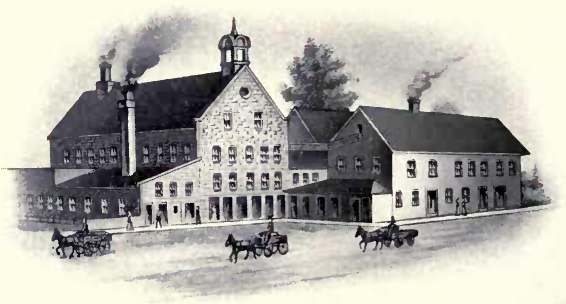

OLD STONE MILL OF WALTER BAKER \& CO. (REBUILT IN I 849 .) name of Baker without interruption from that day to this.

After the death of Dr. James Baker the business fell in the order of succession to his son Edmund and his grandson Walter. On the death of the latter in 1852 , Sidney Williams, who had been his partner for some years, continued in charge of the affairs until he died two years later ( 1854 ), when Henry L. Pierce, a relative of Walter Baker, took the management of the business, first as lessee and later as sole owner. During the forty-two years in which he had control he raised it from a

\footnotetext{
1 History of the Town of Dorchester, Mass., 1857.
} 
comparatively small, local concern to the position of the leading industrial enterprise of its kind on this continent.

In 1895 the business was organized as a corporation under the general laws of Massachusetts; and in 1898 a special charter was granted by the General Court.

The old stone mill which was erected in $18_{49}$, on the site long occupied by the small building shown in the engraving of 1822 , has given place to an imposing structure of brick and stone, known as Mill No. 5 . The plant now comprises six mills on the Dorchester and Milton sides of the Neponset River, containing 348,48 o square feet of floor space about eight acres.

It is an interesting fact that on the spot where the industry was first started, more than a century and a quarter ago, the business has continued and attained the highest development. From the little wooden mill,

"By the rude bridge that arched the flood,"

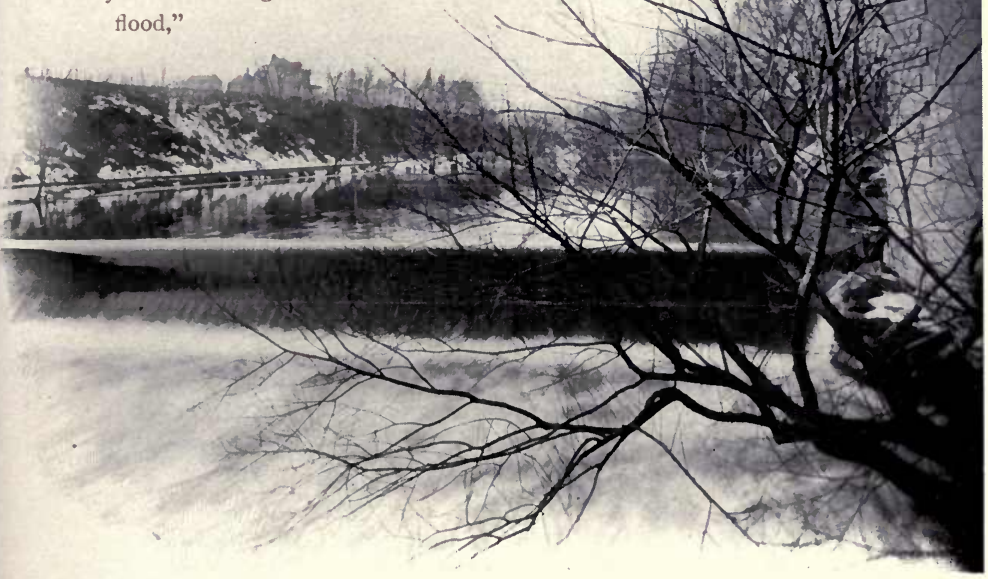

NEPONSET RIVER FALIS. 


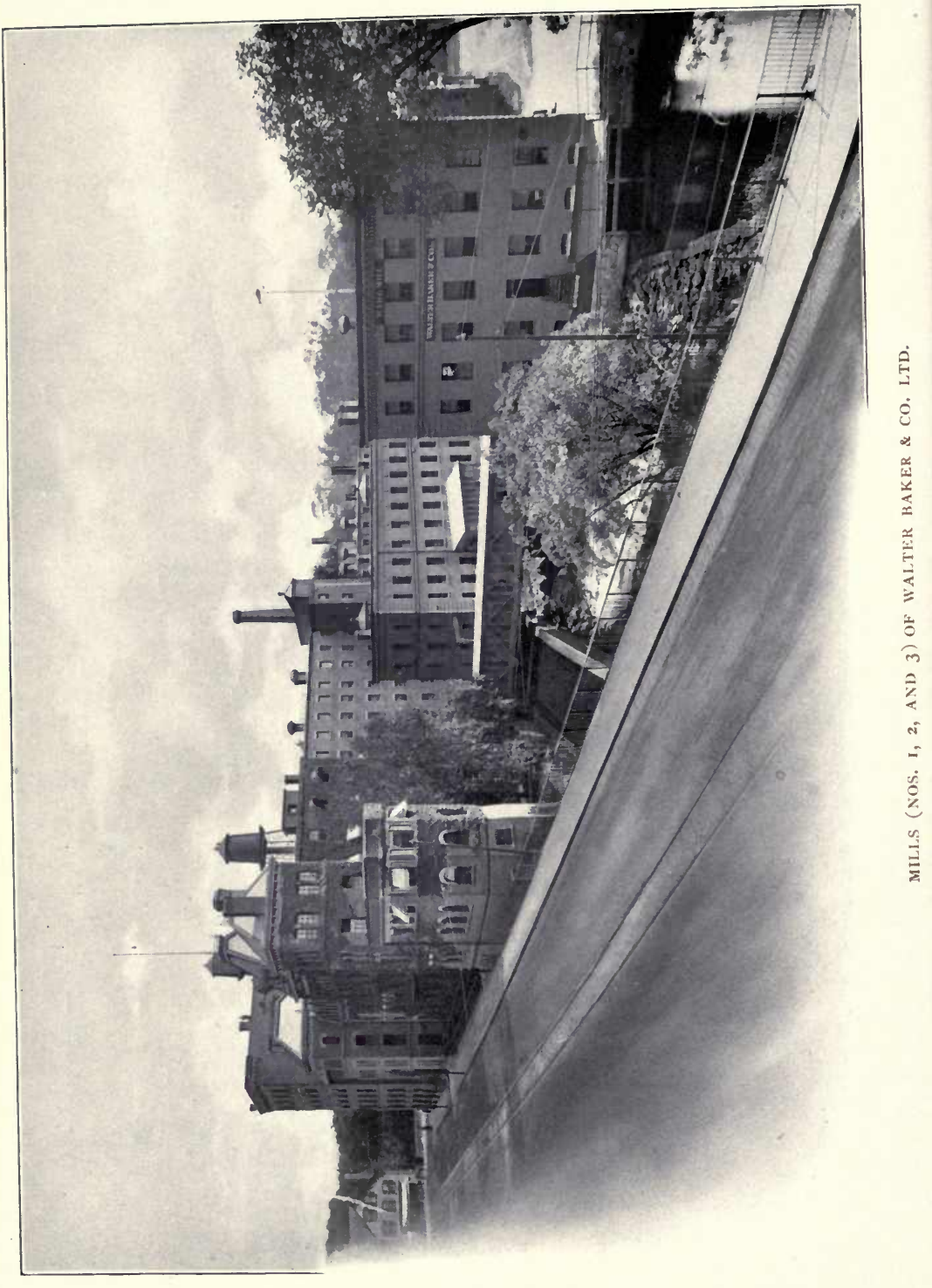


there has grown up one of the greatest establishments in the world, the house of Walter Baker \& Co. Ltd., - an establishment which competes successfully for prizes in all the great industrial exhibitions of the world, whose influence is felt in the great commercial centers, and whose prosperity promotes the welfare of men who labor under a tropical sun in the cultivation of one of the choicest fruits of the earth.

Before proceeding to describe the methods of manufacture used in the Baker Mills, something should be said on the importance of selecting only the best raw materials, and of treating them in the light of modern science and without sophistication.

The three associated beverages, cacao, tea, and coffee, are known to the French as aromatic drinks. Each of these has its characteristic aroma. The fragrance and flavor are so marked that they cannot be imitated by any artificial products, although numerous attempts have been made in regard to all three. Hence, the detection of adulteration is not a difficult matter. De-
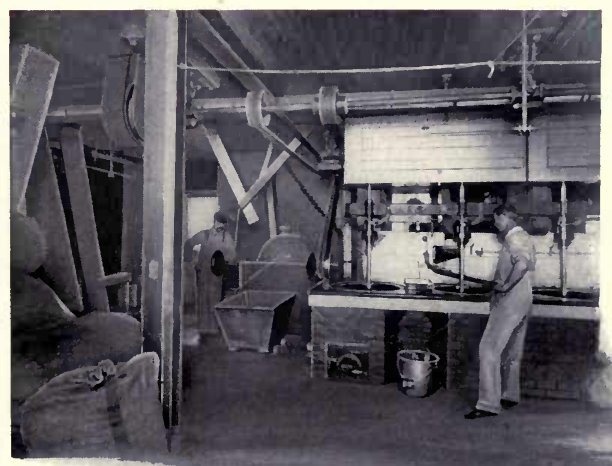

A BIT OF THE OLD MILL - (1N MILL NO. 3 ) signing persons, aware of the extreme difficulty of imitating these substances, have undertaken to employ lower grades, and by manipulation copy, as far as may be, the higher sorts. Every one knows how readily tea and coffee, for that matter, will take up odors and flavors from substances placed near them. This is abundantly exemplified in the country grocery or general store, where the teas and coffees share 
in the pervasive tragrance of the cheese and kerosene. But perhaps it is not so widely understood that some of these very teas and coffees had been artificially flavored or corrected before they reached their destination in this country.

Cacao lends itself very readily to such preliminary treatment. In a first-class article, the beans should be of the highest excellence; they should be carefully grown on the plantation and there prepared with great skill, arriving in the factory in good condition. In the factory, they should simply receive the mechanical treatment requisite to develop their high and attractive natural flavor and fragrance. They should be most carefully shelled after roasting and finely ground without concealed additions. This is the process in all honest manufactories of the cacao products.

Now, as matter of fact, in the preparation of many of the cacao products on the market a wholly different course has been pursued. Beans of poor quality are used, because of their cheapness, and in some instances they are only imperfectly, if at all, shelled before grinding. Chemical treatment is relied on to correct in part the odor and taste of such inferior goods, and artificial flavors, other than the time-honored natural vanilla and the like, are added freely. The detection of such imposition is easy enough to the expert, but is difficult to the novice: therefore the public is largely unable to discriminate between the good and the inferior, and it is perforce compelled to depend almost entirely on the character and reputation of the manufacturer.

Pure cacao-products are characterized by extreme delicacy of flavor. But they possess another feature of attractiveness, - a beautiful rich red-brown color which is so truly characteristic, that its name, "chocolate," has passed into many languages as denoting this charming shade. When the cacao product is pure, this shade is not a very dark brown, it inclines rather to a dark red. When the color of a cacao-product is so dark as to appear almost black it is a sure sign that it has been tampered with in the process of manufacture or else that 
the original cacao-seed was of poor quality. The uninformed person naturally thinks that the deeper shade means strength. This it never means. The black color simply shows that the manufacturer has seen fit to employ harmful alkaline additions at some stage of the process, or perhaps has preferred to color his goods artificially with coal-tar dyes or with the less injurious lampblack. It may be said, once for all, that black cacao-products must be looked upon with suspicion. They contain foreign matters or else they have been maltreated by chemicals during manufacture. Pure products of the cacao-seed preserve their fine delicacy of flavor from start to finish: black products are impure. Discriminating purchasers know this and recognize the fine reddish-brown as characteristic of a pure product, while it is only among those who do not give proper attention to the matter that a market can be found for the cacaos and chocolates to which alkalies, coal-tar dyes, or lampblack have given an unwholesome darkness.

There are few articles in common use where so simple a test for purity exists.

A well-known medical expert has said: "The recent tendency to interfere with the natural properties and constituents of such a valuable food as cocoa is deeply to be deplored. The removal of the fiber and the excess of fat is all that is necessary to produce the most perfect food beverage known to physiologists, and the best cocoa from the dietetic standpoint is undoubtedly that which is perfectly pure without addition of any kind whatsoever. Some manufacturers add starch or sugar in the mistaken idea that starch properly replaces the fat removed. But in no case can starch take the place of fat in a food, and the result is simply to lower the flesh-forming qualities of the cocoa so treated. Starched cocoa is really a poor food, and should be avoided by all who wish to get the most nutriment at the lowest cost in the form of pure cocoa. Malted cocoa, so much in vogue lately, is merely a fad, and has no actual food value over the plain article. The malt is added because it contains a ferment termed 'diastase,' which has the power 
of converting starch into sugar, and if the malt retained this power in the cup of cocoa its inclusion could be defended. But the diastase is killed at 175 deg. Fahr., and therefore the digestive action of the malt is entirely destroyed by the addition of the boiling milk or water to the powder or paste in the cup. Inasmuch as malt is inferior to cocoa in actual food value, its addition to cocoa lowers the nutritive value of the beverage. The use of hops is also entirely useless as far as practical

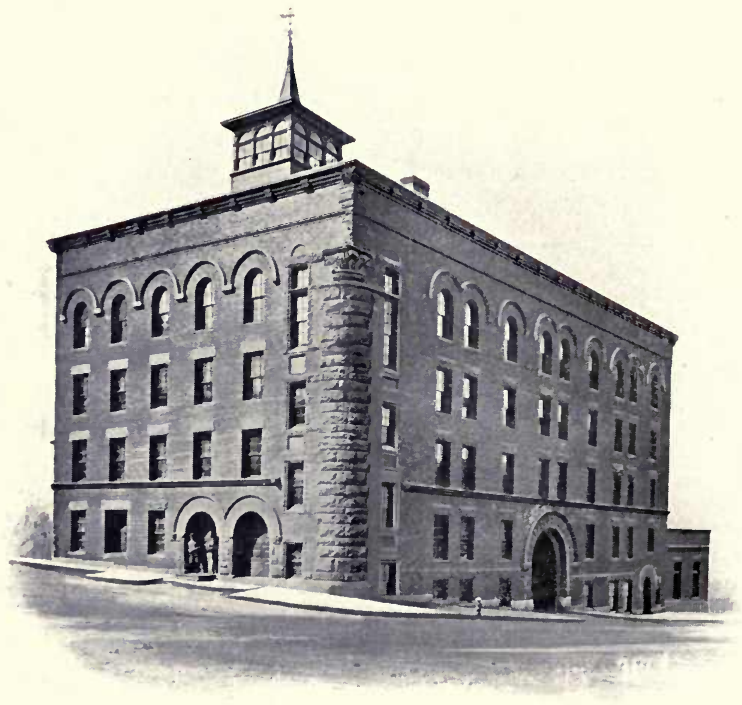

MILL NO. 4, WALTER BAKER \& CO. LTD.

results are concerned, for if sufficient hops were used to be of any service as a tonic to the stomach, the flavor of the cocoa would be so influenced as to make it quite unpalatable, and as the hops have no nutritive value, the addition is without beneficial results. The treatment of cocoa with potash is to be strongly condemned, as the slightly increased solubility obtained is more than counter-balanced by the injurious effects 
of the chemical upon the system, and those who a'alue good health a'ould be well advised to leaz'e such cocoas alonc. Perhaps the most novel departure of late years is the addition of kola to cocoa. Kola is a powerful drug, and contains besides caffeine other potent nerve stimulants of an unknown character. It is impossible to defend on hygienic grounds the addition of such a powerful drug to an article of daily con-

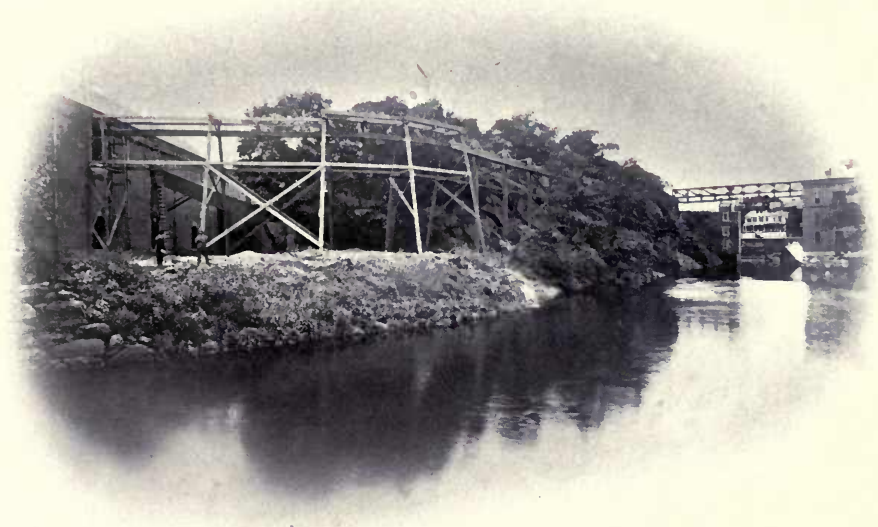

THE TELPHERAGE SYSTEM - FOR THE CONVEYANCE OF CRUDE COCOA FROM THE STOREHOUSES TO THE ROASTIXG ROOMS.

sumption, and though under medical advice, and in exceptional cases, the increase of nerve stimulating properties which kola confers on cocoa may be beneficial, yet to the masses such uncontrolled drugging may be followed by serious consequences. Pure cocoa is so rich in good dietetic properties that to interfere with the normal proportions of the food principles is to notably decrease its nutritive value."

The simple process by which the natives of Central and South America prepared a nutritious beverage from the seeds of the cocoa 
tree has already been described. We will now refer briefly to the modern method of manufacture as carried on in the Walter Baker establishment, in which the latest and most improved machinery and appliances are used to improve the quality and cheapen the cost of production.

The selected cocoa beans are first cleaned from the dust and attached particles which have come from various sources during the fermentation of the seeds. The machines for cleaning the beans are very ingenious and effective, removing from the seed coat every trace of

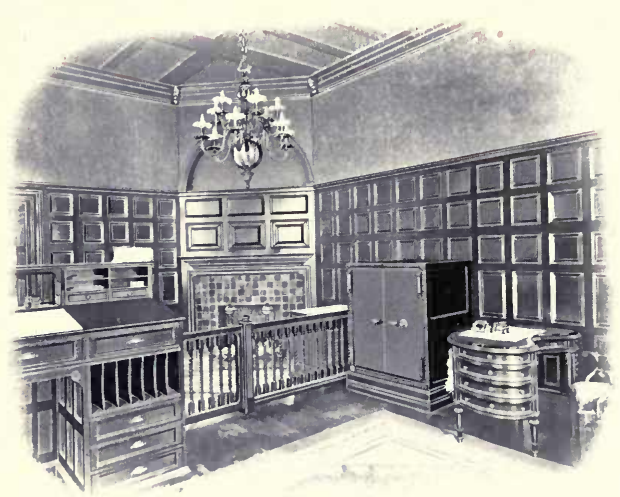

PRIVATE OFFICE, MILL No. 4. foreign matter.

The cleaned seeds are next roasted in the most careful manner, every precaution being taken to secure a uniform effect through the whole mass. During the roasting the seeds change color somewhat and become more or less modified in taste. In under-roasted seeds the flavor is not fully developed, while in over-roasted seeds the pleasant taste is likely to become greatly impaired, or it may even be wholly replaced by a bitter and harsh flavor. These relations of color and taste to the roasting of the seeds make this portion of the manufacture one of the most delicate processes from beginning to end.

By the roasting the shell becomes more readily detachable, and its complete removal is the next step. The crushing of the seeds into small fragments is easily accomplished; and this is followed by a thorough winnowing, by which the lighter shells are carried away by 


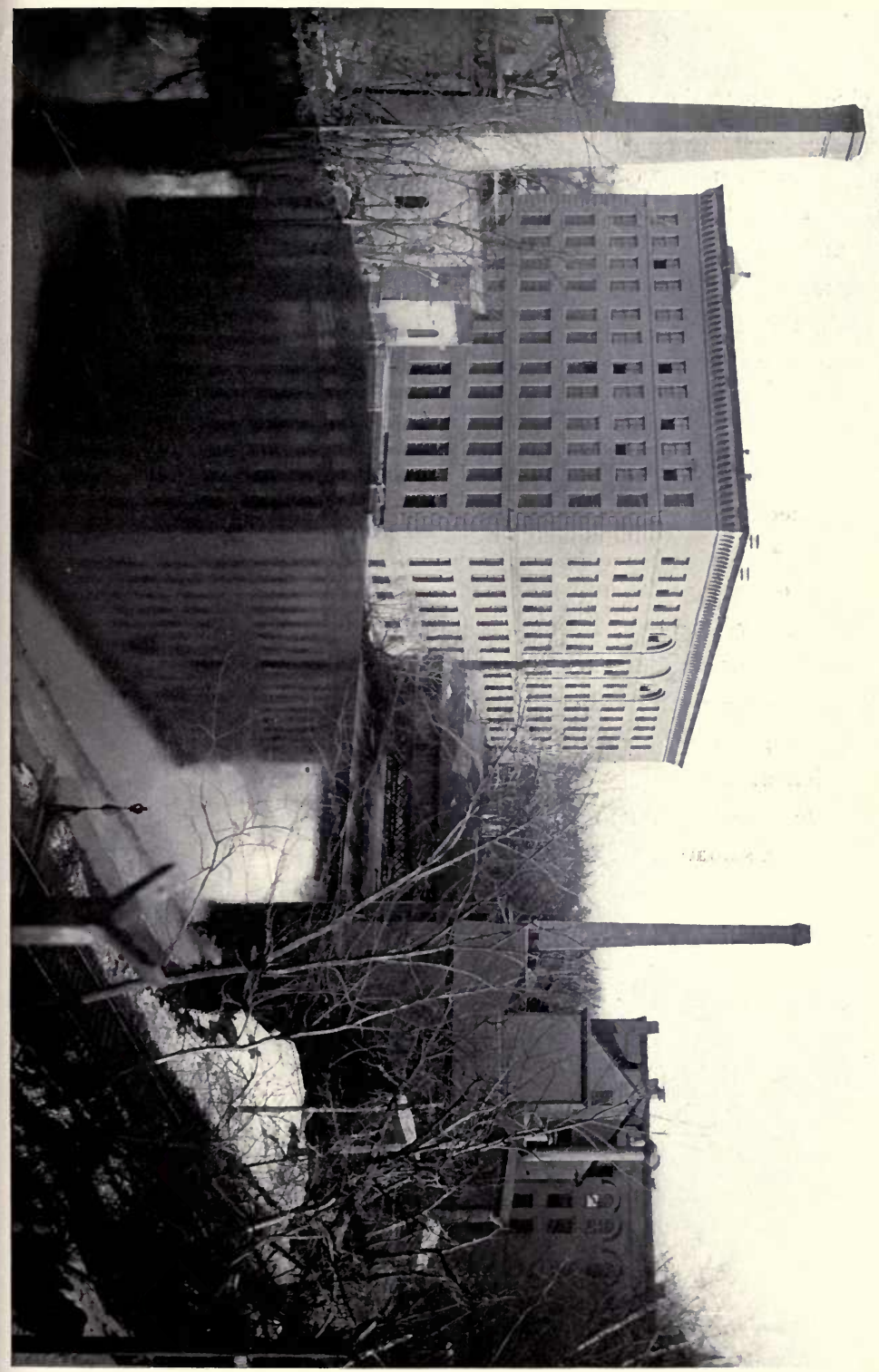


themselves, leaving the clean fragments of the roasted seeds ready for further manipulation.

Among the fragments can be detected minute and very tough bits of tissue. These bits are the hardened germs, or rather portions of the germs, and these are separated from the rest by an apparatus of much simplicity and efficiency.

The clean shells are usually placed at once in packages for transportation. They are extensively used for the domestic preparation of a wholesome and very low-priced drink. This beverage contains a fair proportion of the active principle of the chocolate seeds themselves, and the flavor is suggestive of chocolate.

The cleaned fragments constitute the so-called " cocoa nibs" of some foreign markets, and in this state they are used for the preparation of a simple decoction. But in this form they require to be boiled a good while for the development of flavor, and it is, therefore, better to have them treated beforehand in order to reduce the time of boiling; and this is all the more necessary, since during the long boiling a part of the more delicate aroma peculiar to chocolate seeds is apt to be

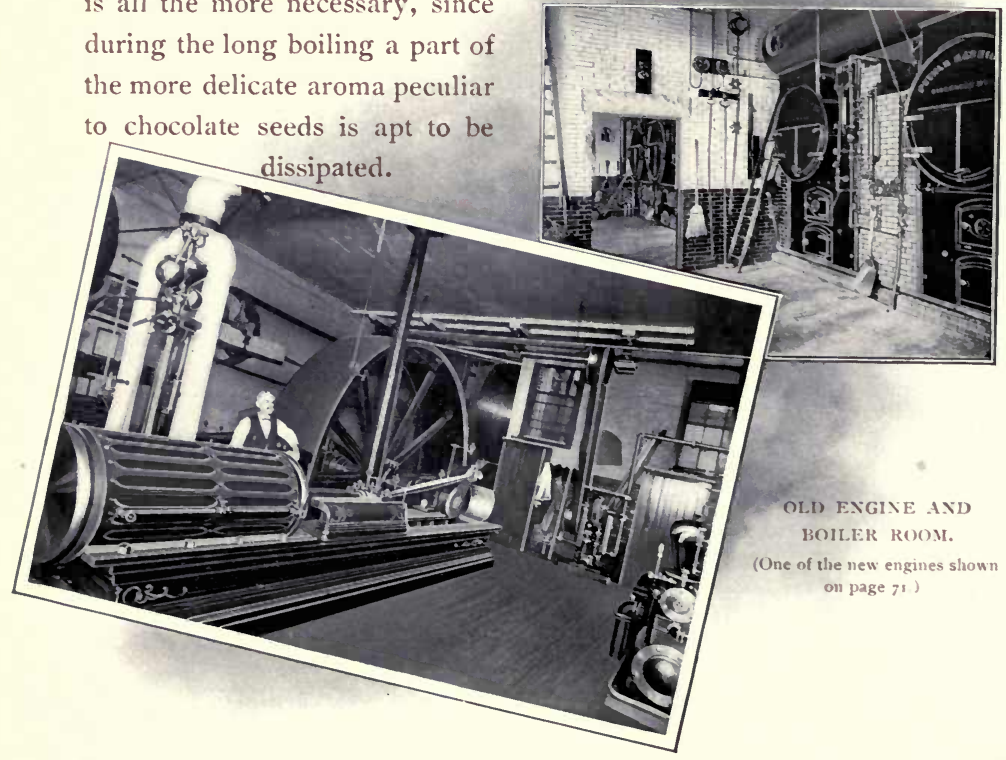


In the preparation of chocolate, the fragments are ground by a complicated mechanism until they attain the greatest degree of rineness, and constitute a perfectly homogeneous mass or paste. If it is to be a plain chocolate (which is put up in a blue wrapper with a yellow label and known as "Baker's Chocolate" or "Premium No. I Chocolate"), it goes directly into the molds for shaping it.

The molding is a noisy but interesting operation. The chocolate

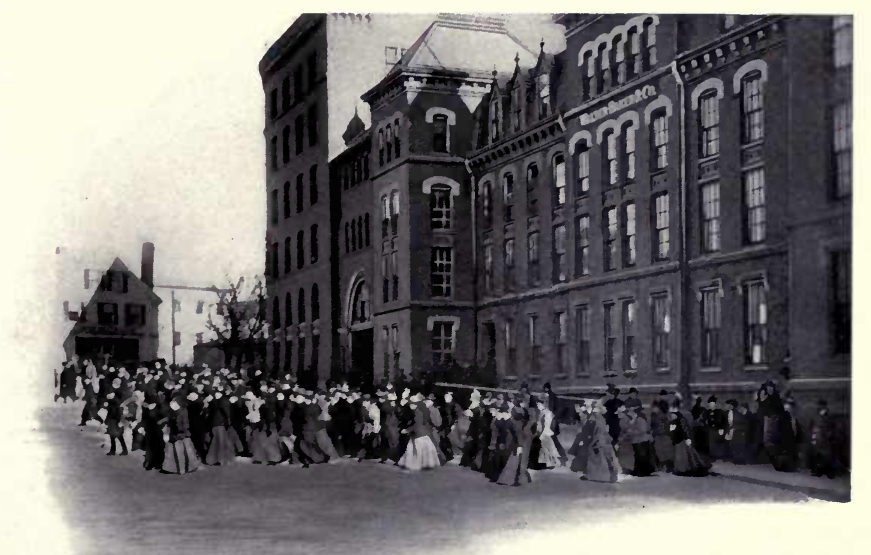

THE NOON HOUR, MILL NO. I.

cannot be pressed into molds, because it sticks to the presser; it is, therefore, shaken in. A plastic lump of the proper weight is placed in a shallow mold. A number of these molds are put into a wooden tray, placed upon a table, which is shaken automatically, causing the metal molds to jump up and down in a very lively manner, and making as much clatter as a regiment of cavalry crossing a bridge. Every step of the process has to be watched with the most assiduous care. When the plastic mass has been shaken into the mold so as to be perfectly uniform in shape and size, the pans are removed to the cooling room. 
If the chocolate is to be sweetened, a definite amount of the purest sugar, previously pulverized, is added before the molding, and the whole ground and commingled. If it is to be a vanilla chocolate, the finest quality of Mexican vanilla beans (which are superior to those grown elsewhere) are blended with the semi-fluid mass, and formed in molds, as already described.

The variations in the process are innumerable, many of them comparatively unimportant when taken singly; but to secure the best

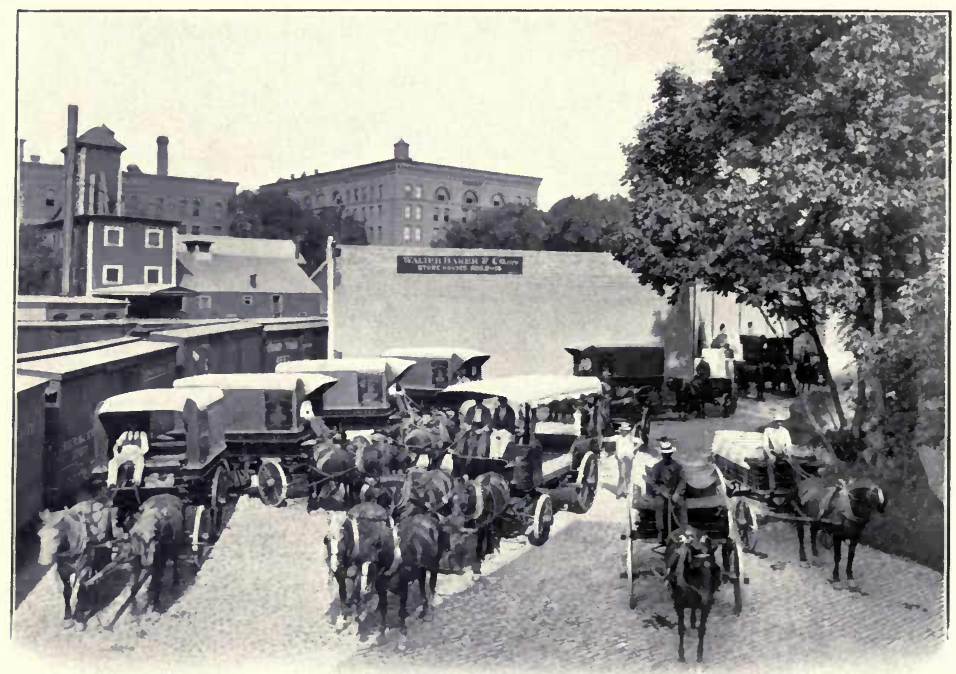

WALTER BAKER \& CO.'S TEAMS.

results it is important that each of these slight changes should be made at just the right time and in the right way.

The manufacture of breakfast cocoa is based upon two important factors: first, the removal of a definite portion of the cocoa-oil from 
the roasted seeds; and second, increasing the miscibility of the powdered seeds by securing the greatest practicable degree of fineness.

While the oil of the chocolate seed is perfectly wholesome, there are some persons who find in the percentage natural to the seeds an amount too large for easy digestion. The removal of a part of this, which might with propriety be called an excess of the oil, was practised even in very early days, as is seen in the cut herewith given, taken from an old work on the subject.

The method of manufacture is substantially as follows: the ground fragments of roasted seeds are subjected to hydraulic pressure, by which a certain amount of the fat is eliminated. The pressed mass is, in the most successful process, treated mechanically in such a manner as to divide and subdivide the minute particles until they are capable of passing through a sieve having several thousand meshes to the square inch. But such pulverization as this would, under ordinary circumstances, reduce the mass to a dull and unattractive powder. In the process devised by the Walter Baker Company, this high degree of fineness is secured without any loss of brilliancy in the powder, - the color being

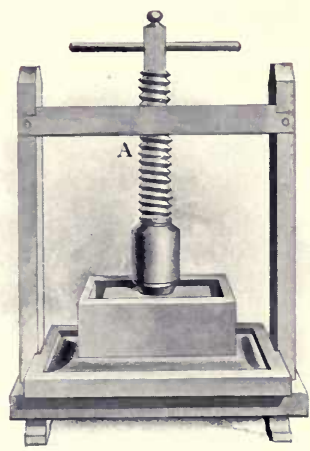

OLD PRESS FOR REMOYING EXCESS OF OIL. of the bright red which is not only attractive in appearance, but when conjoined with the natural chocolate odor and flavor is characteristic of absolutely pure cocoa of the highest grade.

It is instructive to compare such cocoa with the cocoas prepared by what is known as the Dutch process. The latter are prepared by treatment with alkaline matters, which act on the coloring substances in the seeds, increasing the apparent effect of hot water when the latter is added. In chemically prepared cocoas, the exquisite natural odor and flavor of pure cocoa seeds have been diminished 
or wholly lost by the severe treatment to which the materials have been subjected. In some cases the loss of the natural flavor is sought to be partially supplied by the use of fragrant gums, and other matters wholly foreign to the natural product.

The detection of these admixtures is generally easy. Comparison

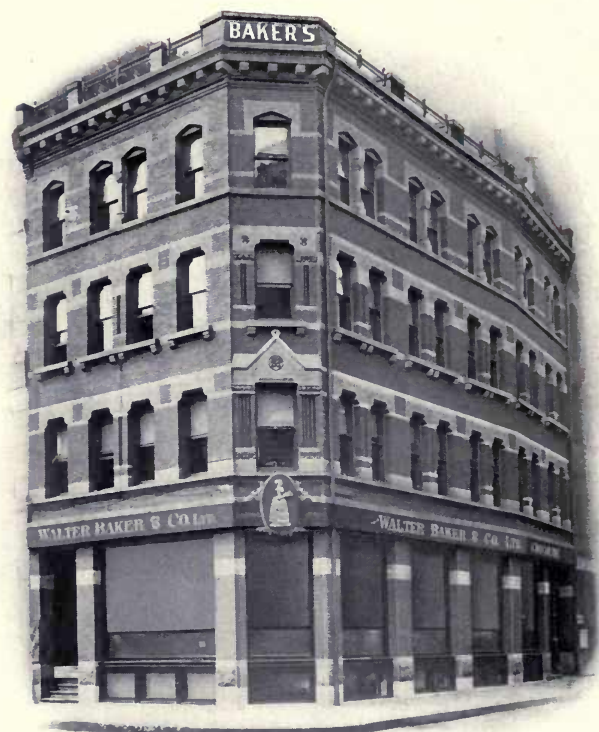

EXECUTIVE OFFICES, 45 BROAD STREET, BOSTON.

with Baker's Breakfast Cocoa will reveal at once the vast superiority of a product which has not been treated by chemicals, but which contains only the finest possible powder of the best chocolate seeds freed from the excess of oil. The exquisite flavor and odor of the pure product are due wholly to the seeds themselves, since absolutely no foreign 
matter is added from first to last. It can be used by students of the microscope and of chemistry as a perfect type of the highest order of excellence in manufacture.

Dr. H. C. Sawyer, in his valuable little book on "Nerve Waste," says : -

“Baker's Breakfast Cocoa is a light preparation which can be heartily recommended; it contains only so much fat as can be digested

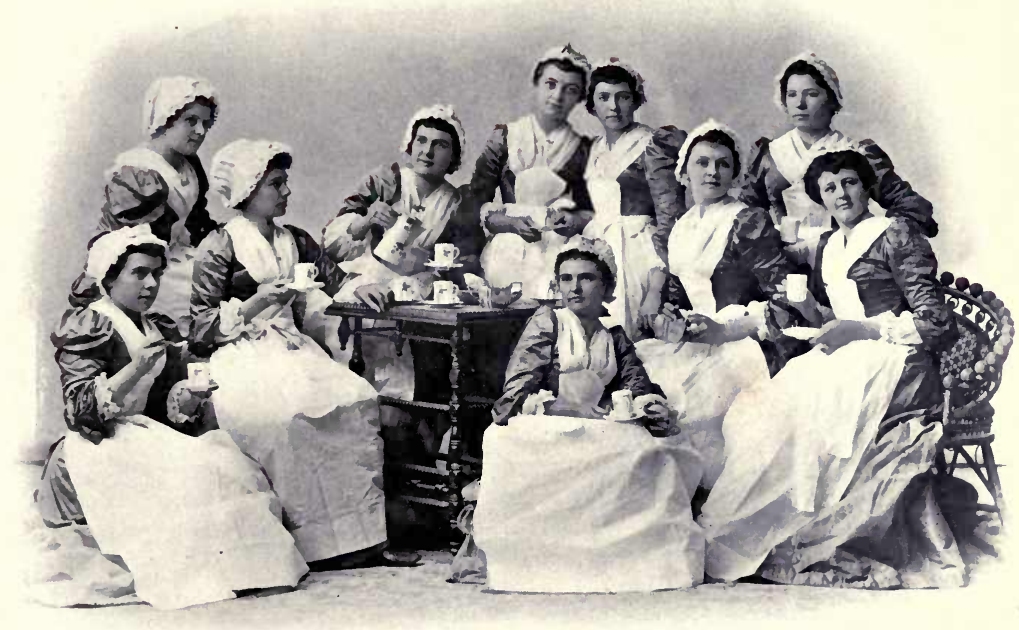

GROUP OF DEMONSTRATORS, WALTER BAKER \& CO. I.TD.

by almost any one, and is peculiar in not cloying or palling after a time as so many cocoa preparations do. Such a beverage is far more wholesome, and more agreeable, after one becomes used to it, than tea, which is much over-used."

A recent article in the New York Polyclinic says :-

"It is not infrequent that chemists and physicians differ in opinion as regards the use of certain food products and their influence upon tissue metabolism; but for many years they have agreed that cocoa 


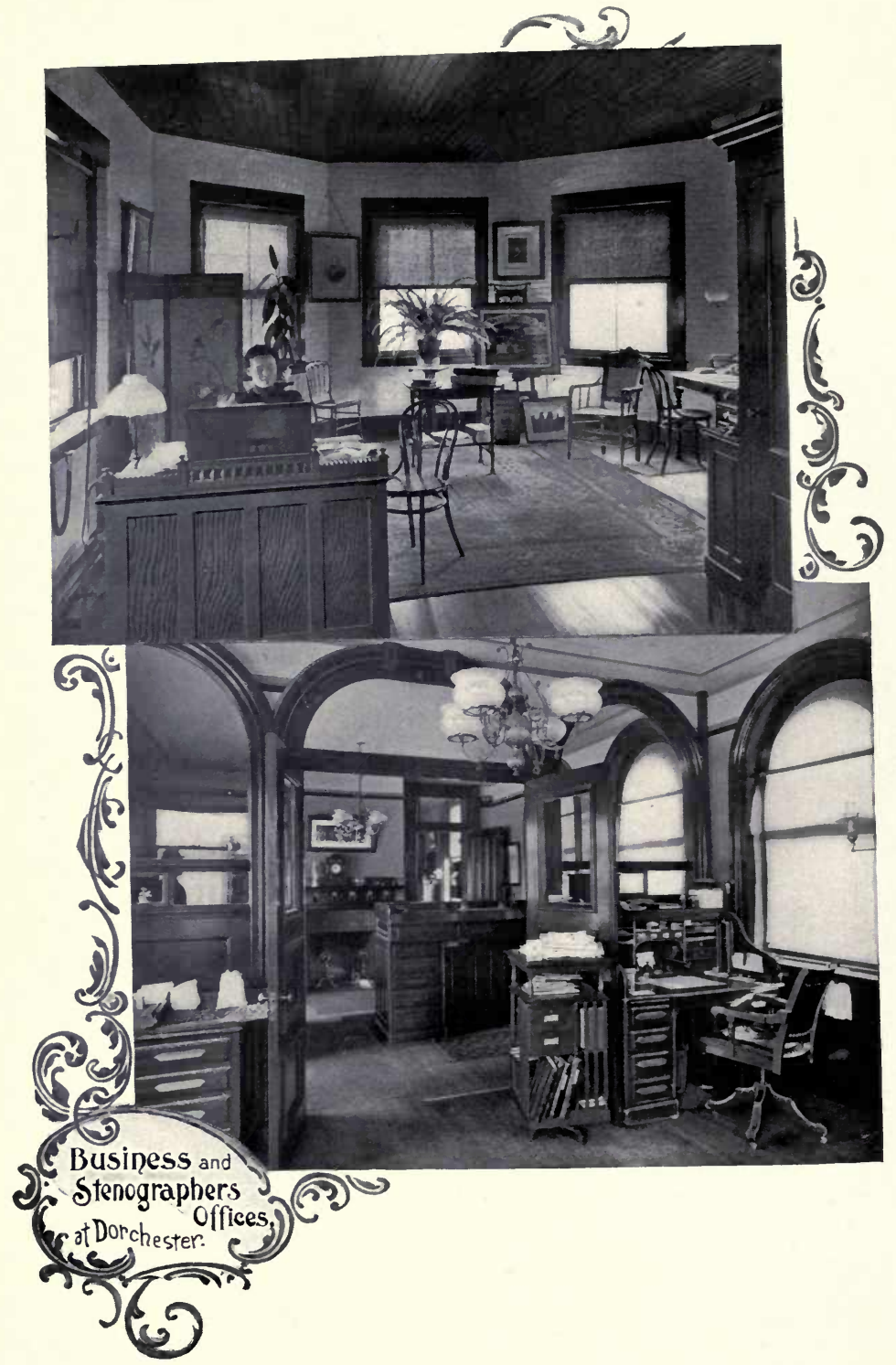


(theobroma cacao) exerts an influence upon the human system that is equaled by no other vegetable product. Careful analysis, combined with extensive clinical experience, has shown beyond shadow of doubt that it retards retrograde metamorphosis of the body tissues (tissue waste), is far more nutritious and less directly stimulating to the nervous system than either tea or coffee, and when the excess of oil (oleum

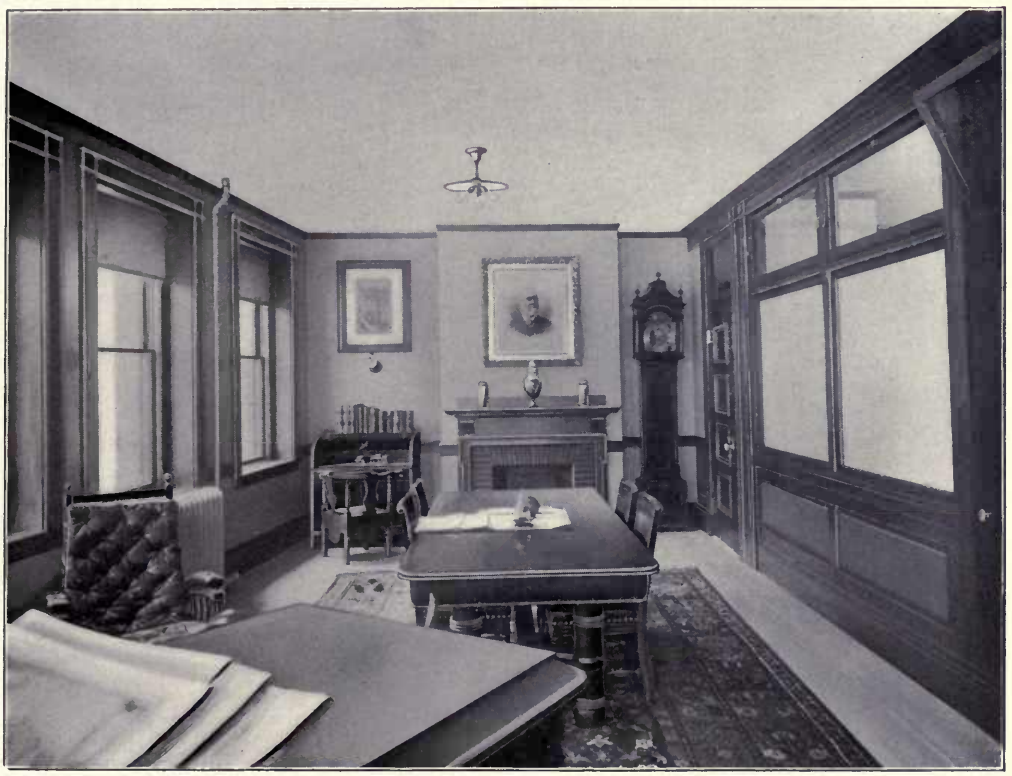

PRESIDENT'S OFFICE, BOSTON.

theobroma) has been removed, exerts a distinctive beneficial influence upon the digestive functions. Such being the case, the use of a thoroughly reliable preparation of cocoa should be universally encouraged, and it is the consensus of opinion among medical men as well as laboratory workers that the breakfast cocoa manufactured by 
Walter Baker \& Co. Ltd., not only meets the indications, but accomplishes even more than is claimed for it."

The Dietetic and Hygicnic Gazette says:-

“Walter Baker \& Co., of Dorchester, Mass., U. S. A., have given years of study to the skilful preparation of cocoa and chocolate, and have devised machinery and systems peculiar to their methods of treatment, whereby the purity, palatability, and highest nutrient characteristics are retained. Their preparations are known the

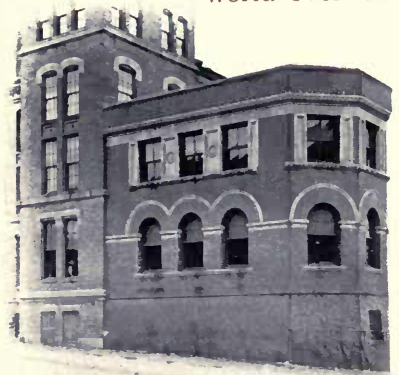

OFFICE BUILDING, DORCHESTER. from the medical practitioner, the nurse, and the intelligent housekeeper and caterer. There is hardly any food product which may be so extensively used in the household in combination with other foods as cocoa and chocolate; but here again we urge the importance of purity and nutrient value, and these important points, we feel sure, may be relied upon in Baker's cocoa and chocolate."

The Dominion Medical Monthly, Toronto, Canada, says :" There are on the market to-day a large number of so-called cocoas, all of them 'guaranteed' to be 'absolutely pure,' but many of them adulterated. There are few articles which physicians find as much use for as this preparation of the cacao nut, and one of the difficulties which medical men have to overcome is to choose the pure from the impure, choosing the former and discarding the latter. Many persons declare firmly that they cannot digest cocoa, this being due to a certain degree of oiliness present. Pure cocoa acts as a gentle stimulant, and invigorates and corrects the action of the digestive organs, furnishing the body with some of the purest elements of nutrition. The 


$$
\text { THE HOUSE OF WALTER BAKKER \& CO. }
$$

firm of Walter Baker \& Co. Ltd., of Dorchester, Mass., put up one of the few really pure cocoas, and physicians are quite safe in specifying their brand."

The American Homeopathist says :-

"The need of a substitute for coffee in many nervous disorders, and

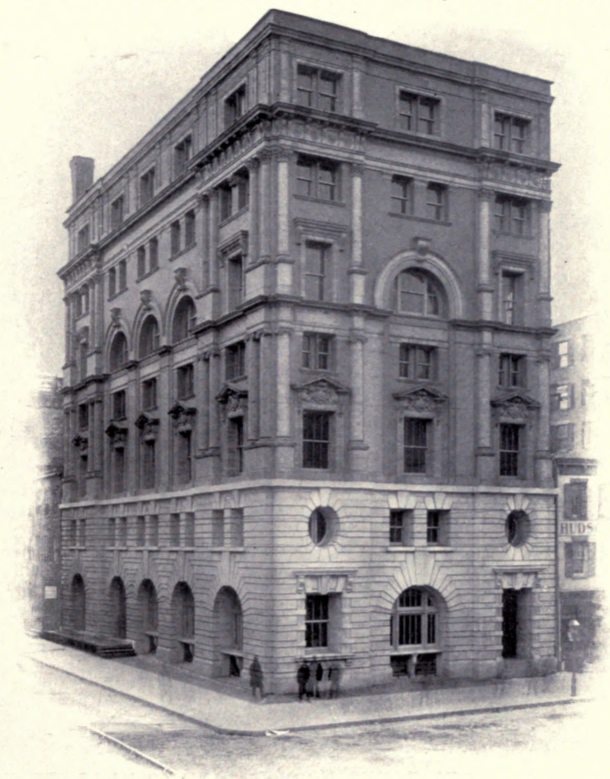

BRANCH HOUSE OF WALTER BAKER \& CO. LTD.

FRANKLIN AND HUDSON STREETS, NEW YORK.

particularly where there are heart complications, has induced me to give special recognition to the cocoa preparations, for all are not of equal merit. The essentials of a proper production are found in the well-known cocoa made by Walter Baker \& Co., of Dorchester, Mass., and in one or two others, but I give preference to the one named, because it is always and everywhere obtainable and is of uniform quality. 
Its usefulness is not, however, restricted. In many cases of deficient nutrition, it may be well prescribed as a food-drink with every meal."

The Maryland Medical Journal says:-

" Physicians have long recognized the valuable dietary properties of cocoa. When obtained free from any admixture of foreign matter, its

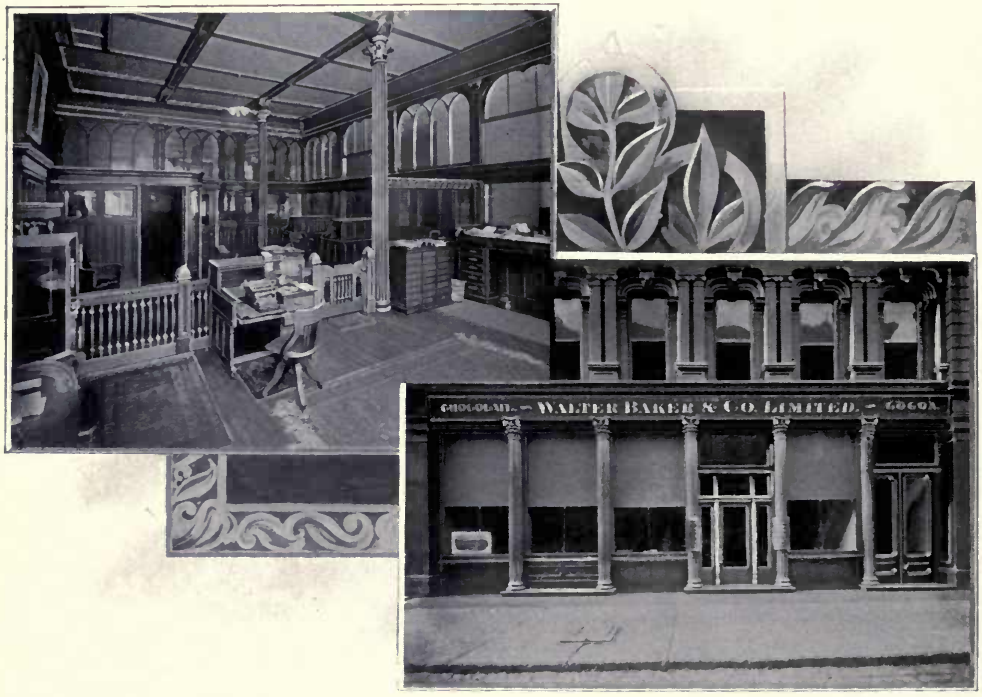

BRANCH HOUSE OF WALTER BAKER \& CO., 38 AND 40 LAKE STREET, CHICAGO.

nutritive value cannot be overestimated, combining as it does in proper proportion the essentials of a perfect food - carbohydrates, albuminoids, mineral matters, and the active principle, theobromine. The physiological effects of cocoa in certain constitutional derangements are well known to practitioners in general, and when no violence is done to the chemical properties of the different components in the process of preparation a product at once comforting and nutritious is 
obtained. The wholesomeness and efficiency of the Walter Baker \& Co.'s Cocoa is due to a peculiar process in its manufacture, which preserves the theobromine and nutritive portion without the use of chemicals, and has more than three times the strength of other preparations mixed with starch, arrowroot, or sugar. The long-standing reliability of this brand of cocoa enables physicians to prescribe it with thorough confidence in its highly valuable nutritive effects and full assurance of its purity and wholesomeness."

The Health Magazine says :-

" A very large class of intelligent and right-thinking people throughout the world are ready to testify to the nutritive properties of Walter Baker \& Co.'s Breakfast Cocoa. The food value of this article has so long been known to physicians and the public that it has become in a great many homes a staple article of the dietary, not only for invalids, but for persons in health as well."

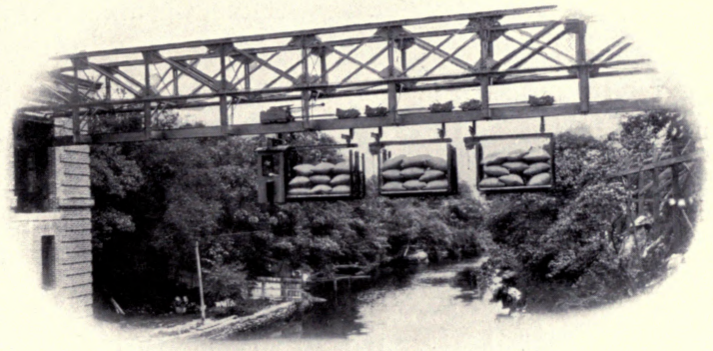

A DETAIL OF THE TELPHERAGE SYSTEM. 


\title{
SUGGESTIONS
}

\author{
RELATIVE TO
}

\section{THE COOKING OF CHOCOLATE AND COCOA.}

BY MRS. ELLEN H. RICHARDS,

Of the Massachusetts Institute of Technology.

$\mathrm{T}$

HE flavor of the cocoa bean seems to be almost universally liked, and the use of the various preparations made from it is constantly increasing. From the sweet chocolate with which the traveler now provides himself in all journeys in which the supply of food is doubtful either in quantity or quality, to delicate coloring and flavoring of cakes and ices, nearly all kinds of culinary preparations have benefited by the abundance of this favorite substance.

In these forms, chocolate is used in a semi-raw state, the bean having been simply roasted at a gentle heat, ground and mixed with sugar, which holds the fat. By varying the quantity of the chocolate to be mixed with the ingredients of the cake or ice, an unlimited variety of flavors can be obtained.

In preparing it as a beverage for the table a mistake has been frequently made in considering chocolate merely as a flavor, an adjunct to the rest of the meal, instead of giving it its due prominence as a real food, containing all of the necessary nutritive principles. A cup of chocolate made with sugar and milk is in itself a fair breakfast.

There is much to be said in favor of preparations of the whole bean which secure all of the valuable nutrition contained in this "food for the gods," and rightly understood, it is possible to make them more important articles of diet than they now are. But since the large percentage of fat seems to require correspondingly large quantities of 
sugar to render the beverage palatable, and this very rich, sweet drink soon cloys if made strong enough to be nutritious, it is, fortunately, possible to extract the larger part of the fat without injury to the flavor so characteristic of chocolate. In this form, called cocoa, less sugar and more milk are needed, and the resulting beverage suits even delicate stomachs, and is yet of high food value.

It is the object of all cooking to render raw material more palatable and more nutritious, and therefore more digestible. The cooking of cocoa and chocolate is no exception to this rule. Certain extractive principles are soluble only in water which has reached the boiling point; and the starch, which the seed contains, is swollen only at this temperature.

Chocolate or cocoa is not properly cooked by having boiling water poured over it. It is true that as the whole powder is in suspension and is swallowed, its food material can be assimilated as it is when the prepared chocolate is eaten raw ; but in order to bring out the full, fine flavor and to secure the most complete digestibility, the preparation, whatever it be, should be subjected to the boiling point for a few minutes. In this all connoisseurs are agreed.

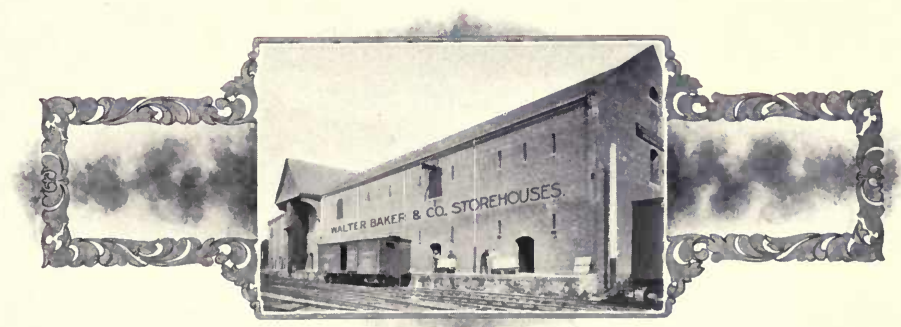

WALTER BAKER \& CO.'S STOREHOUSES, MILTON. 


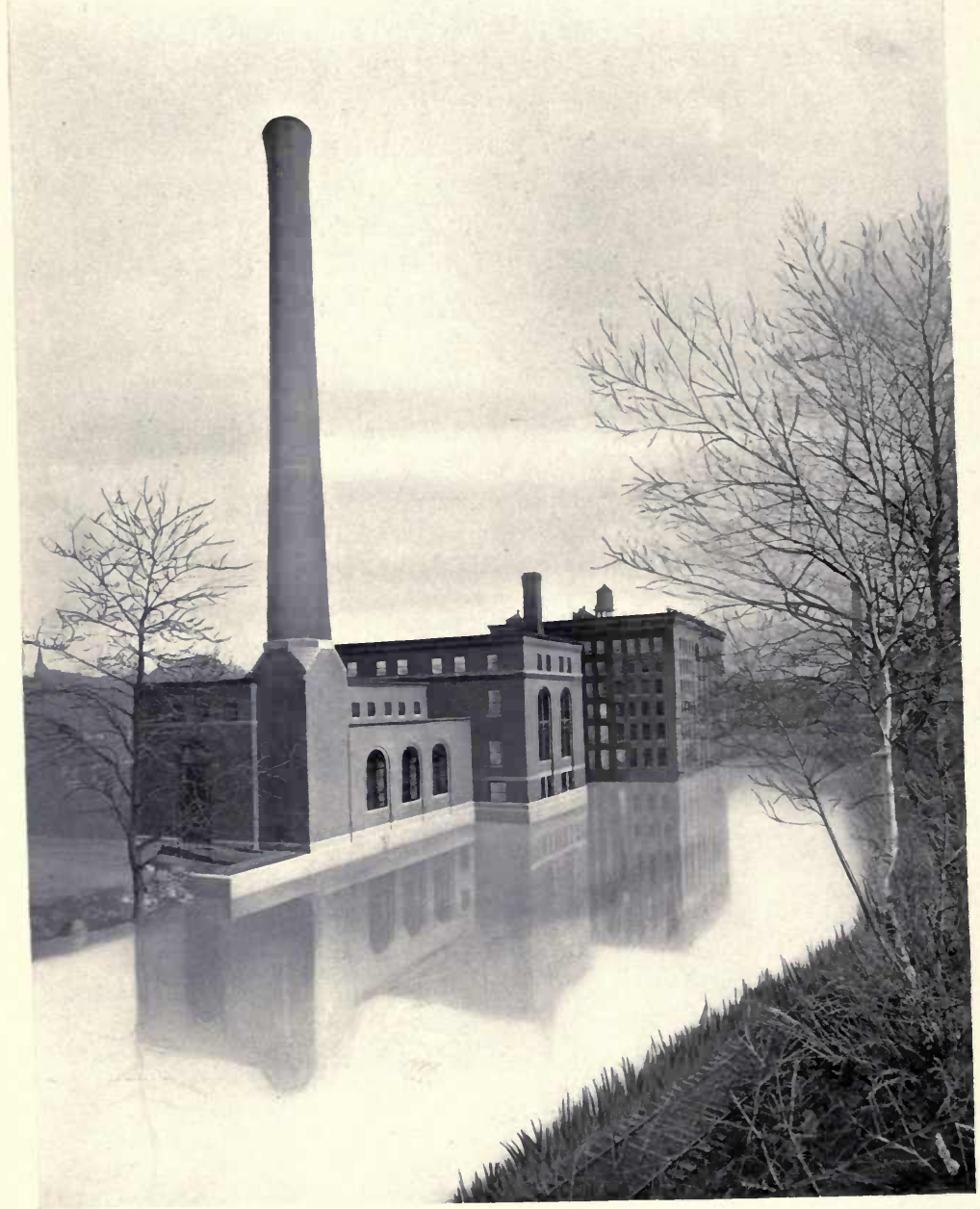

NEW POWER PLANT, I9O6, WALTER BAKER \& CO. LTD. 


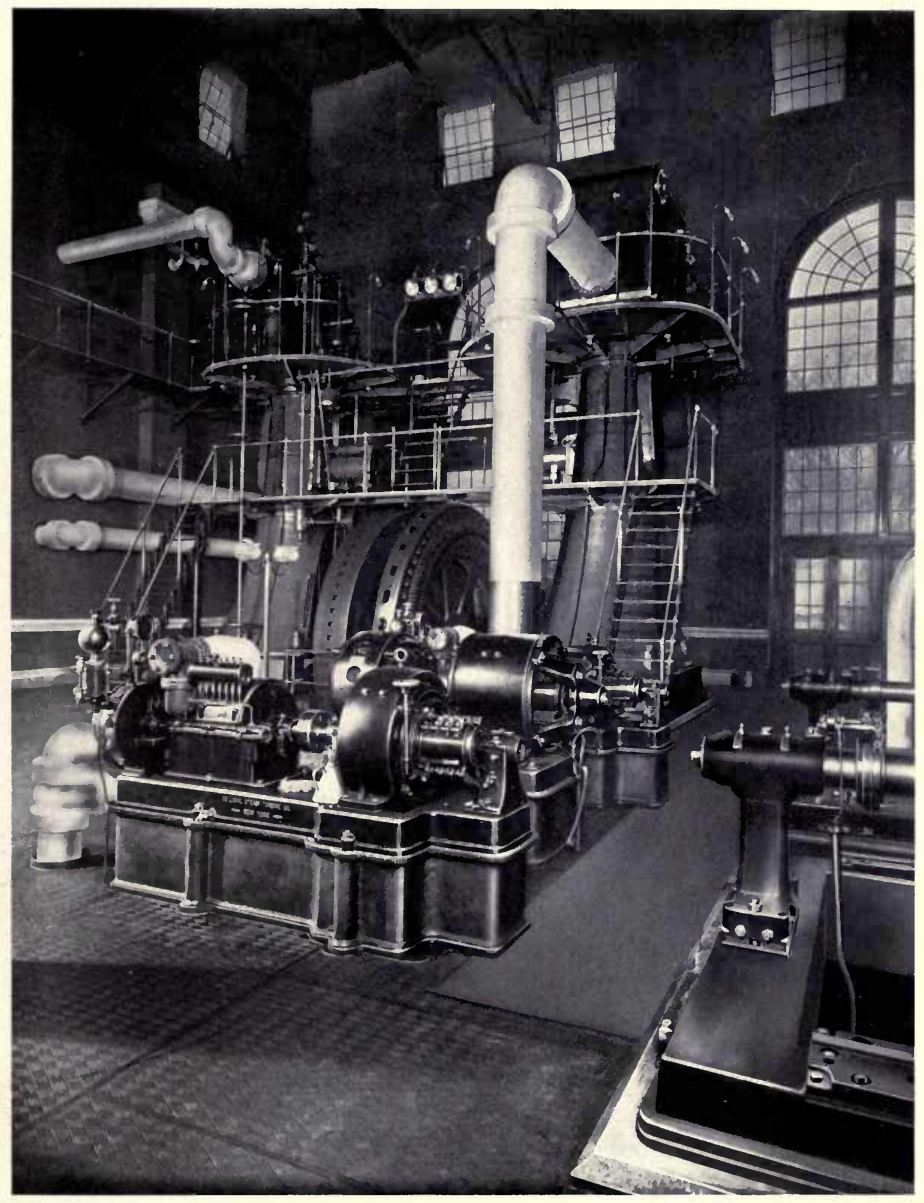

ONE OF THE ENGINES IN THE POWER HOUSE. 


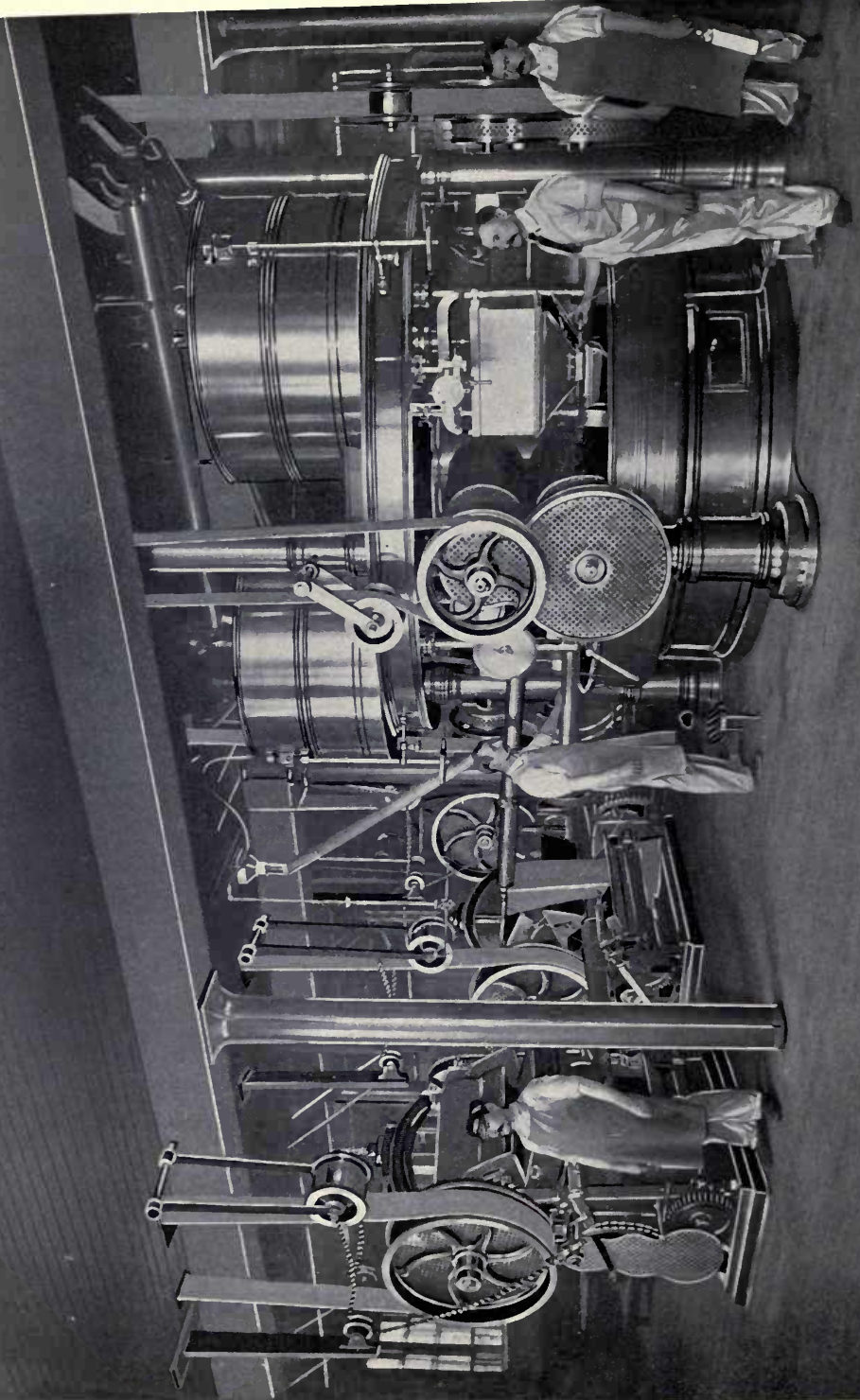




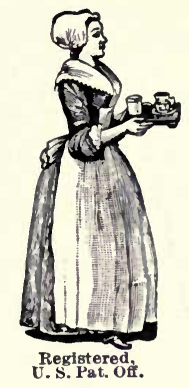

\section{BAKER'S BREAKFAST COCOA.}

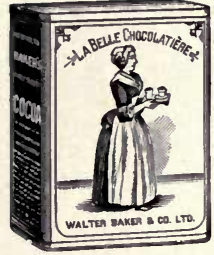

No alkalies or other chemicals or dyes are used in its preparation.

Trade-mark on every package.

\section{BAKER'S CHOCOLATE.}

In $1 / 216$. cakes, 1 lb. packages, bluse wrapper, yellow label.

It is the pure product of carefully selected cocoa beans, to which nothing has been added and from which nothing has been taken away. Unequaled for

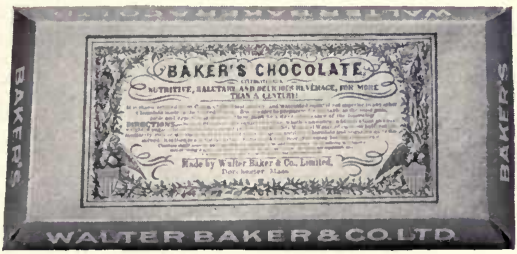

smoothness, delicacy, and natural flavor. Celebrated for more than a century as a nutritious, delicious, and flesh-forming beverage. The high reputation and 
constantly increasing sales of this article have led to imitations on a very extensive scale. To distinguish their product from these imitations Walter Baker \& Co. Ltd. have enclosed their pound packages in a new envelope or case of stift paper, different from any other package. The color of the case is the same shade of deep blue heretofore used on the Baker packages, and no change has been made in the color (yellow) and design of the label. On the outside of the case, the name of the manufacturer is prominently printed in white letters. On the back of every package a colored lithograph of the trade-mark, "La Belle Chocolatière," sometimes called the Chocolate Girl, is printed. Vigorous proceedings will be taken against any one imitating the package.

Trade-mark on every package.

\section{BAKER'S VANILLA CHOCOLATE,}

In $1 / 2 \mathrm{lb}$. and $\frac{1}{6} \mathrm{lb}$. packages,

is guaranteed to consist solely of choice cocoa and sugar, flavored with pure vanilla beans. Particular care is taken in its preparation, and a trial will convince one that it is really a delicious article for eating or drinking. It is the

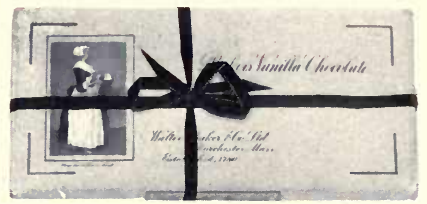

best sweet chocolate in the market. Used at receptions and evening parties in place of tea or coffee. Our choice Recipe book (sent free) contains a valuable recipe for making the Chocolate with Whipped Cream.

Trade-mark on every package.

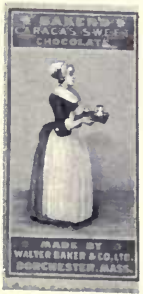

\section{CARACAS SWEET CHOCOLATE.}

In $1 / 4 \mathrm{lb}$. packages and $6 \mathrm{lb}$. boxes.

Unequaled for smoothness, delicacy, and flavor. The most delicious and healthful article of food that can be carried by golfers, bicyclists, tourists and students.

Trade-mark on every package.

\section{CENTURY CHOCOLATE.}

In $1 / 4 \mathrm{lb}$. packages.

A fine vanilla chocolate for eating or drinking. Put up in very artistic wrappers.

Trade-mark on every package. 


\section{AUTO SWEET CHOCOLATE.}

In 1-6 lb. packages.

A fine eating chocolate, enclosed in an attractive wrapper with an embossed representation of an automobile in colors.

Trade-mark on every package.

\section{GERMAN SWEET CHOCOLATE.}

In $1 / 4$ and $1 / 8 \mathrm{lb}$. packages.

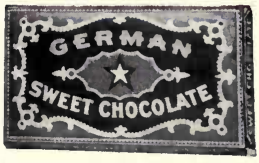

is one of the most popular sweet chocolates sold anywhere. It is palatable, nutritious, and healthful, and is a great favorite with children.

Bezuare of imitations. The genuine is stamped " $S$. German, Dorchester, Mass."

Trade-mark on every package.

\section{CRACKED COCOA, OR COCOA NIBS.}

In $1 / 2$ and $1 \mathrm{lb}$. packages and in 6 and $10 \mathrm{lb}$. bags.

This is the freshly roasted bean cracked into small pieces. It contains no admixture, and presents the full flavor of the cocoa bean in all its natural fragrance and purity. When properly prepared, it is one of the most economical drinks. Dr. Lankester says cocoa contains as much flesh-forming matter as beef.

Trade-mark on every package.

\section{CACAO DES AZTÉQUES.}

In boxes, $6 \mathrm{lbs}$. each; $1 / 2 \mathrm{lb}$. bottles.

A compound formerly known as Racahout des Arabes; a most nutritious preparation; indispensable as an article of diet for children, convalescents, ladies, and delicate or aged persons. It is composed of the best nutritive and restoring substances, suitable for the most delicate system. It is now a farorite breakfast beverage for ladies and young persons, to whom it gives freshness and embonpoint. It has solved the problem of medicine by imparting something which is easily digestible and at the same time free from the exciting qualities of coffee and tea, thus making it especially desirable for nervous persons or those afflicted with weak stomachs.

It has a very agreeable flavor, is easily prepared, and has received the commendation of eminent physicians as being the best article known for convalescents and all persons desiring a light, digestible, nourishing, and strengthening food.

Trade-mark on every package. 


\section{SOLUBLE CHOCOLATE.}

This is a preparation for the special use of druggists and others in making hot or cold soda. It forms the basis for a delicious, refreshing, nourishing, and strengthening drink.

It is perfectly soluble. It is absolutely pure. It is easily made. It possesses the full strength and natural flavor of the cocoa bean. No chemicals are used in its preparation.

The directions for making one gallon of syrup are as follows :-

8 ounces soluble chocolate.

$81 / 2$ pounds white sugar.

$2 \mathrm{I} / 2$ quarts water.

Thoroughly dissolve the chocolate in hot water, then add the sugar, and heat until the mixture boils. Strain while hot. After it has become cool, vanilla may be added if desired.

The trade is supplied with 1,4 , or $101 \mathrm{~b}$. decorated canisters.

Trade-mark on every package.

\section{CHOCOLATES FOR CONFECTIONERS' USE.}

These chocolates have long been the synonym for purity and excellence. To meet the requirements of the trade, both light and dark chocolate coverings have been prepared from selected cocoas, which, on account of their uniformity, purity, and flaz'or, are favorite brands with all the leading confectioners.

\section{VANILLA TABLETS.}

These are small pieces of chocolate, made from the finest nuts, and done up in fancy foil. The packages are tied with colored ribbons, and are very attractive in form and delicious in substance. They are much used for desserts and collations, and at picnics and entertainments for young people. They are strongly recommended by physicians as a healthy and nutritious confection for children.

Trade-mark on every package. 


\section{COCOA BUTTER.}

\section{In $1 / 2 \mathrm{lb}$. cakes.}

One-half the weight of the cocoa bean consists of a fat called "cocoa butter," from its resemblance to ordinary butter. It is considered of great value as a nutritious, strengthening tonic, being preferred to cod-liver oil and other nauseous fats so often used in pulmonary complaints. As a soothing application to chapped hands and lips, and all irritated surfaces, cocoa butter has no equal, making the skin remarkably soft and smooth. Many who have used it say they would not for any consideration be without it. It is almost a necessary article for every household.

\section{Trade-mark on every package.}

\section{COCOA SHELLS.}

In $1 \mathrm{lb}$. packages.

Cocoa shells are the thin outer covering of the beans. They have a flavor similar to but milder than cocoa. Their very low price places them within the reach of all; and as furnishing a pleasant and healthy drink, they are considered superior to tea and coffee.

Packed only in I lb. papers, with our label and name on them.

Trade-mark on every package. 
Forty-eight highest awards have been received from international and local expositions in Europe and America during the past fifty-two years, of which the following are the most noteworthy.

World's Fair, St. Louis (Grand Prize on all Cocoa and Chocolate and Gold Medal on Installation) · . 1904

Dominion of Canada Industrial Exposition . . 1903 Pan-Ayerican Exposition, Buffalo . . . . . igo I Expositions Universelle, Paris . . 1868, 1878, 1900 Trans-Mississippi, Omaha . . . . . . . . . .

Cotton States and International Exposition, Atlanta . . . . . . . . . . . . . . 1895

Midwinter and International Exposition, San Francisco . . . . . . . . . . . . . . 1894 World's Columbian Exposition, Chicago . . . 1893 International Fair, Detroit . . . . . . . 1892 Exposition Provinciale, Quebec . . . . . . I89i

Massachusetts Charitable Mechanics Association, Boston . . . . . . . . $1853,1878,1890$

World's Industrial and Cotton Centennial, New Orleans . . . . . . . . . . . . . . . . $188_{4}$

Southern Exposition, Louisville . . . . . . $\quad$ i 883

Centennial Exposition, Philadelphia . . . . . 1876 International Exposition, Vienna . . . . . 1873 Industry of all Nations, New York . . . 1853 Franklin Institute, Philadelphia . . . . . $185^{2}$ 


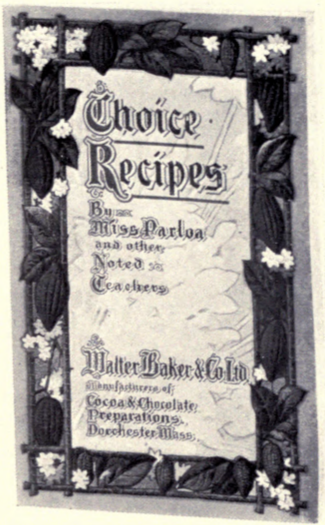

Reduced facsimile of an attractive booklet of sixty-four pages, with colored illustrations, sent free to any applicant. Address

WALTER BAKER \& CO. LTD.,

Dorchester, Mass. 
V 



Unive

So

$L$ 